\title{
Valency mismatches and the coding of reciprocity in Australian languages
}

\author{
Nicholas Evans, Alice Gaby and Rachel Nordlinger \\ University of Melbourne
}

\begin{abstract}
Reciprocals are characterized by a crossover of thematic roles within a single clause. So, in John and Mary wash each other, each of John and Mary is both washer and washed, both agent and patient. The competing pressures to distinguish and merge the reciprocating argument(s) are resolved by different languages in complex and illuminating ways which often create special argument configurations not found in other clause types. While some languages either encode reciprocals by clearly bivalent, transitive clauses (like Warlpiri or English), or clearly monovalent, intransitive clauses (like Wambaya or Yukulta), other languages adopt a mixed or apparently ambivalent solution.

In this paper, based on an extensive sample of Australian languages, we develop a typology of apparent valency/transitivity mismatches in reciprocal constructions including: (a) monovalent clauses with a single ergative NP; (b) mismatches between case marking and the number of arguments encoded on auxiliaries or by pronominal affixes to the verb; (c) the use of ergative marking on secondary predicates and instrumentals with a nominative subject; and (d) complex clause constructions sensitive to valency. Such mismatches, we argue, result from an 'overlay problem' by which both divalent and monovalent predicates in the semantic representation of prototypical reciprocal scenes have had a hand in shaping the morphosyntax of reciprocal constructions through grammaticalization.
\end{abstract}




\section{Introduction ${ }^{1}$}

Reciprocal constructions arguably contain one of the most complex mappings of semantics into morphosyntax, since they involve the overlaid projection of more than one proposition onto a single clause, made more complex by the permutation of the semantic roles associated with the participants concerned. The semantic representations of examples like 'John and Mary kissed / quarrelled with each other' are, on a widely held view (Langendoen 1978, Nedjalkov 1991, Dalrymple et al 1998, Langendoen \& Magloire 2003), generally held to comprise the projection of two predicates whose arguments are permuted: ${ }^{2}$

(1) John and Mary kissed each other / quarrelled with each other.

kiss $(\mathrm{j}, \mathrm{m}) \&$ kiss $(\mathrm{m}, \mathrm{j})$

quarrel_with $(j, m) \&$ quarrel_with $(m, j)$

But it is also arguable that, at least as far as the semantics of the reciprocal prototype goes, there is a further semantic component involving joint activity, coordination and/or mutual feedback. ${ }^{3}$ There can, of course, be reciprocal examples where no such

\footnotetext{
${ }^{1}$ We thank the following people for their valued comments, questions and data in response to written and/or oral presentations of this material: Wayan Arka, Alexis Dimitriadis, Martin Everaert, Bill Foley, Dirk Geeraerts, Brian Joseph, Mary Laughren, Steve Levinson, Michele Loporcaro, James McCloskey, Marianne Mithun, David Nash, Rob Pensalfini, Jane Simpson, and Jean-Christophe Verstraete. Oral versions were presented at the University of Melbourne (June 2003), the ALT summer school on typology in Cagliari, Sardinia (September 2003), the Australian Linguistics Society meeting in Newcastle, Australia (September 2003), Katholieke Universiteit Leuven (October 2003) and the University of Utrecht (October 2003); we thank the audiences of those talks for additional feedback. Finally, we extend our thanks to the Australian Research Council for its financial support of our research (Project: Reciprocals Across Languages).

${ }^{2}$ Once there are more participants the semantic representations get more complex and are normally then stated in terms of quantifiers with lambda operators, but for two participants these are intertranslateable with the simpler predicate calculus versions given here. Since the complexities arising with multiple participants are orthogonal to the issues focused on in this paper we do not discuss them here.

${ }^{3}$ See Evans (2006) for further discussion of this position, including evidence from a range of construction types not examined in this paper, including the Amele 'zig zag' construction (roughly: John and Mary kiss-he-her-DS kiss-she-him-DS they.two.did) and the Japanese verb compounding
} 
coordination or joint activity is involved, as in "the meteorites landed quite close to each other'. The existence of such examples is probably the reason why the 'joint action' component is not generally discussed in the literature on the semantics of reciprocals. However, we believe that, to the extent that it studies the semantic motivations for particular structures as distributed cross-linguistically, typology must pay just as much attention to the semantics of prototypes as to the conditions that apply to all members of a category. This is because, as the functionalist and grammaticalization literatures have told us in many places, it is the commonest uses that tend to shape structure.

The events most commonly described by reciprocal constructions ${ }^{4}$ either involve close and interactive interpersonal coordination to achieve the event - as in the whole amatory set from dancing with each another, kissing each other, making love to each other, marrying each other - or causal feedback, as when each move in a quarrel or fight precipitates the next move. ${ }^{5}$ For this reason we believe it is reasonable to postulate the following rough ${ }^{6}$ representation for the semantics of prototypical reciprocal clauses:

(2) j \& m V-ed each other

construction (roughly: John and Mary kiss-met). Both Amele and Japanese combine verbs representing one-way action with another summative verb representing joint action.

${ }^{4}$ See Kemmer (1993) for a list of 'naturally reciprocal events' - operationally definable as those expressed in languages by the morphologically minimal construction type.

${ }^{5}$ Further evidence for the centrality of joint action and mutual causation in prototypical reciprocals comes from the grammaticalization sources - and/or formal sharing - between reciprocal markers and comitative/sociatives (see e.g. Maslova 1999, to appear) on the one hand, and reciprocal markers and causatives on the other: languages where causative elements are linked with reciprocal marking include Amharic, Tigrinya, Arabic (all Semitic), Nakanai (Austronesian) and Piro (Maipuran Arawakan), among others - see Kulikov (2001). There are also languages which have grammaticalized reciprocal markers from verbs meaning 'compete', which involves both mutual causation and joint action: Tuvaluan (Besnier 2000) is a good example.

${ }^{6}$ Obviously this is a provisional representation only, since ultimately a more rigorous definition of 'act jointly' needs to be given - see Clark \& Carlson (1982) for an interesting discussion, but this suffices for current purposes. 
$\mathrm{V}(\mathrm{j}, \mathrm{m})$

$\mathrm{V}(\mathrm{m}, \mathrm{j})$

Act.jointly (j\&m)

Reciprocal constructions - or at least the large subset of the cross-linguistically attested range of reciprocal construction types that are monoclausal ${ }^{7}-$ thus need to accomplish a complicated projection of arguments from semantics to syntax, since each participant appears in three roles: individually as both the first and the second arguments of a two-place predicate (owing to the cross-over of roles), and, additionally, as a subset of the argument of a one-place predicate.

Note that this revised representation for the semantics of (prototypical) reciprocals overlays projections from both two-place and one-place predicates onto a single clause. This is in situations where the base predicate is divalent, as with 'kiss' or 'quarrel with'. In the case of three-place verbs, like 'they showed each other their tattoos' or 'they gave each other a present', the valence of the monovalent joint-action predicate stays the same, but the one-way predicates are now trivalent. We thus overlay two three-place and one one-place predicate. The relevance of these cases will become clear in $\S 5$, when we discuss reciprocals of trivalent verbs.

Since spoken languages lack the possibility of representing two or more propositions simultaneously, ${ }^{8}$ one would expect on first principles that there be conflicting motivations here, resulting in a range of outcomes cross-linguistically in how these constructions are encoded, and this is exactly what we find. At a gross level ${ }^{9}$ the commonest choices are either to treat the reciprocal clause as a transitive,

\footnotetext{
${ }^{7}$ See König \& Kokutani (2006) and Evans (forthcoming) for typologies of reciprocal construction types.

${ }^{8}$ See Haiman (1980:433) for the point that an iconic representation of the semantic structure of reciprocals would require a 'acoustically impossible' structure in which both $\mathrm{V}(\mathrm{j}, \mathrm{m})$ and $\mathrm{V}(\mathrm{m}, \mathrm{j})$ are uttered at once, so that languages must find somewhat less iconic means of representing simultaneity iconically 'within the constraints imposed on human speech, which can put things together only "horizontally". It is significant that in many varieties of sign language, where this constraint is removed, at least some types of reciprocal action (e.g. fighting) are able to be shown iconically through symmetric gestures in which each hand simultaneously undertakes the same movement (Zeshan \& Panda forthcoming).

${ }^{9}$ Again, there are in fact many other possibilities, which we do not consider in this paper - see Evans (forthcoming) for a comprehensive treatment.
} 
typically filling the antecedent argument slot with a regular NP and the other with a reciprocal expression like 'each other', as is familiar from English (1), or to derive an intransitive verb by adding a special reciprocal marker to the verb, as in Mundari (3), which makes the intransitive status of reciprocal clauses particularly clear through the presence of an intransitive suffix (-ke) on the verb in addition to the lack of any object pronominal suffix.

(3a) Soma $=\tilde{n} \quad$ lel-ki-q-i-a

MUNSoma-1sgSUBJ see-COMPL-TR-3sgOBJ-IND

'I saw Soma.'

(3b) Soma ad añ do=ling

$l e<p e>l-k e-n-a$

MUNSoma and $1 \mathrm{sg}$ TOP=1du.exclSUB see $<$ REC $>$-COMPL-INTR-IND

'Soma and I saw each other.'

At first blush, these two strategies appear to reflect a straightforward choice between 'transitive' and 'intransitive' ${ }^{10}$ strategies for coding reciprocals, depending on which propositions in the semantic representation - the two-place or one-place elements - have prevailed in shaping the projection of meaning onto construction type: arguably the English construction in (1) bases its core syntax on one of the oneway predicates ( $X$ saw $Y$ ), while the Mundari construction in (3) bases it on the intransitive predicate $X \& Y$ saw jointly. Typological correlations between the strategy for encoding a reciprocal, and the valency of the resultant clause, have been proposed

\footnotetext{
${ }^{10}$ We will use 'valency' to mean the number of semantic and/or syntactic arguments (as appropriate), and 'transitivity' to refer to a broader set of morphosyntactic characteristics: intransitive morphosyntactic features are those associated with canonical monovalent clauses, and transitive morphosyntactic features are those associated with canonical divalent ones. Though aligning in prototypical cases, there are many ways in which the two dimensions can be detached. 'Look for' or 'wait for', for example are divalent but not transitive in many languages (e.g. English, Kayardild), and it is often the valency rather than the transitivity which is relevant for reciprocal formation (e.g. Kayardild can employ the reciprocal suffix -nyju-/nthu- with jani- 'look for' and ngaka- 'wait for' as well as with straightforward transitives). Since most of our sources describe the issues in terms of transitivity we will retain the terms intransitive and transitive in cases where no confusion arises, but we believe the fundamental issues reflect mappings between semantic and syntactic valency, and so will phrase our discussion in those terms as far as possible.
} 
by a number of investigators (see $\S 2$ below): namely, that languages employing verbal affixes reduce the valency, while languages employing NP-like markers of reciprocity (such as the binomial quantifier each other) will leave the valency unaffected. These proposals hold up well on an overall statistical basis, although there are some exceptions (see §6.2).

However, our focus in this article will be on languages where things are not so simple: where reciprocal constructions exhibit a mixture of features, some normally associated with bivalent constructions and others with monovalent ones. This, we claim, reflects the respective effects of the two-place and one-place propositions in the semantic representation, as grammaticalized into morphosyntactic form. As happens generally in situations where competing motivations are at work, different factors prove more or less important in different languages, but what is clearly discernible cross-linguistically are the distinct outcomes of these two pressures.

We draw on a sample of 22 Australian languages from 8 language families ${ }^{11}$ (see Table 1), chosen either because they exhibit relevant mixed behaviour or because the descriptions of the language are detailed enough to give evidence of consistency in either monovalent or bivalent behaviour across a range of indicators. We examine how consistent languages are in their resolution of these competing motivations. In the process, we expand the typology of grammatical domains and constructions in which these conflicts are played out.

[Table 1 about here]

Australian languages prove a particularly well-suited laboratory for examining this issue, for two main reasons. First, they are a large set of ultimately-related but typologically varied languages with a range of finely calibrated responses to the coding challenge mounted by reciprocals. Second, they possess certain typological

\footnotetext{
${ }^{11}$ With around 26 language families in the continent (see Evans 2003b) this samples about a third of the genetic diversity. For many families, though, there are either insufficient materials to assess the questions discussed in this paper (e.g. Gaagudju - Harvey 2002), the constructions are irrelevant to the question (e.g. the biclausal constructions found in the Iwaidjan languages - see Evans, Singer \& Birch forthcoming) or available materials simply indicate that there is a reduction in transitivity, without material or discussion indicating any deviations from a consistent intransitivizing strategy (e.g. Wardaman - Merlan 1994).
} 
features which supply a range of independent lines of evidence, thus providing us with an armory of different diagnostics for valence and/or transitivity. Third, the conjunction of rich case-marking with widespread morphological ergativity furnishes a ready litmus (though not always a straightforward one) of transitivity. Fourth, there are a large number of constructions displaying some sort of case-linking between a $\mathrm{NP}$ and its antecedent (secondary predication, linked body parts, case agreement of nominalized clauses with their antecedents); in many cases these behave as if linked to arguments which, on first inspection, appear not to be there.

As we shall see in $\S 3$, different Australian languages furnish ample exemplification of languages that adopt 'clean' solutions on one side or the other: in some, reciprocals appear to leave valency untouched, while in others, the constructions are monovalent on a whole range of indicators. Alongside these, however, are languages in which different components of the grammar point different ways, one clausal subsystem treating reciprocals as if they were monovalent, while another treats them as if their valency was the same as the corresponding unidirectional clause; we analyse these in $\S 4$ (bivalent clauses) and $\S 5$ (trivalent clauses). Finally, in $\S 6$, we return to some general issues for the typology of argument projection in reciprocals that our overview has raised.

\section{Previous work on transitivity and valency in reciprocals}

Even though the main focus of our article is on reciprocals, since most previous work on transitivity and argument structure in reciprocals has built on or related it to similar phenomena in reflexives, it makes sense in this section to take the two phenomena together. Note in advance that a majority of the Australian languages we deal here with use the same marker for the two functions, and in a worldwide sample of 175 languages (Maslova \& Nedjalkov 2005), 32\% of languages surveyed exhibited formal identity between reflexive and reciprocal constructions. ${ }^{12}$

\footnotetext{
${ }^{12}$ This figure includes $9 \%$ where there are 'both reflexive and non-reflexive reciprocal constructions' (like German, where Sie hassen sich 'they hate each other/themselves' exemplifies the former and Sie hassen einander 'they hate each other' the latter), and $25 \%$ where the reciprocal and reflexive constructions are formally identical. Within their Australian sample of 16 languages, there is formal identity of reflexives and reciprocals in $37.5 \%$.
} 
However, others (e.g. Kayardild, Yukulta, Kuuk Thaayorre) distinguish them, and contrasting reciprocal and reflexive affixes in the same post-root position can be reconstructed to a very deep level in Australian languages (Alpher, Evans \& Harvey 2003). There is also evidence from at least some languages, such as Bininj Gun-wok (Evans 2003a) and Dalabon (Evans field notes), that reciprocal and reflexive uses of the same form interact differently with applicatives and with divalent verbs. In both these languages the benefactive applicative may feed the reciprocal, but not the reflexive: they-BENefactive-meat-cook-RR can mean 'they cooked meat for each other' but not 'they cooked meat for themselves'.

In both reflexive and reciprocal constructions, such as 'John and Mary saw themselves in the mirror' or 'John and Mary saw each other in the mirror', coreference makes the argument structure anomalous relative to canonical constructions. In reflexives, there is straightforward coreference between the reflexive expression 'themselves' and its antecedent subject 'John and Mary'. In reciprocals, the coreference relation is more complex: standard logical treatments treat the "each other' expression as setting up a situation with a 'polyadic quantifier that binds two variables in its scope, both variables ranging over one set, the restricted domain of the quantification' (Dalrymple et al 1998:183). Effectively, this distributes the predicate over each possible pairing between members of the reference set, i.e. (John, Mary) in 'John saw Mary' and (Mary, John) in 'Mary saw John'. ${ }^{13}$ Though it is clear that semantically there are two participant roles (e.g. a seer and a seen, or an agent and patient), it is less clear how many syntactic arguments there are (see Mohanan \& Mohanan (1998) for detailed discussion of this question), and as we have already seen

\footnotetext{
${ }^{13}$ The distributive nature of the relation is most clear in languages like English, where 'each other' is effectively a fusion of the two elements making up the distributive expression 'each member of $\{\mathrm{X}, \mathrm{Y} .$.$\} acts upon the other member(s) of \{\mathrm{X}, \mathrm{Y} . .$.$\} '. Indeed, some logical treatments of reciprocity$ derive the semantics rather directly from the semantic and combinatorial properties of the English terms each and other (see Heim, Lasnik and May 1991). The relation is much less iconic, however, in languages where the predicate is intransitivized (see $\$ 3.2$ below), and also in languages where the relevant arguments are simply represented by pronouns (free, reduced or bound) referring to the whole set. An example is Sa (Oceanic, Vanuatu; Evans fieldnotes), where 'they shot each other' is ir-ben-ir [they.two - shoot - they.two] (also interpretable as 'they two shot the other two' and 'they two shot themselves'). This phenomenon is common in the languages of Vanuatu and New Caledonia: see Osumi (1995:207-8) on Tinrin, Moyse-Faurie (1995) on Xaracuu, and Bril (2003) on several other languages of New Caledonia.
} 
some languages treat reciprocal constructions as straightforwardly transitive while others treat them as straightforwardly intransitive; similar points can be made for reflexives.

\subsection{Faltz's generalization}

Leonard Faltz (1985:14-15), in the first monograph-length typological survey of reflexives, gave the following account of why, in many languages, reflexive constructions are realized as intransitives:

$[\mathrm{T}]$ here is a clear connection between reflexivization and intransitivity. Namely, by coreferentially tying together the agent and patient of a transitive predicate, the reflexive renders that predicate a function of one argument only, hence equivalent to an intransitive. Diagrammatically, we may say that, when the transitive predicate $\mathrm{P}(\mathrm{x}, \mathrm{y})$ is used reflexively, it becomes ...

$\mathrm{P}(\mathrm{x}, \mathrm{x})=\mathrm{P}_{\mathrm{R}}(\mathrm{x}) \ldots$

The two sides of the equals sign ... suggest two ways a grammar can mark a reflexive. On the one hand, the subject-object coreference can be shown in the subject and/or object noun phrases themselves. On the other hand, the verb can be modified as a signal that it is being used reflexively, the modified verb (or "reflexive verb") now participating in an intransitive clause structure. ${ }^{14}$

\footnotetext{
${ }^{14}$ Faltz does not ignore, however, the fact that verb-coded reflexives may exhibit subtle evidence for the presence of object NPs at some level of representation - see particularly the Kinyarwanda and Lakhota examples he discusses on pp. 188-198, in which certain syntactic processes can only be understood in terms of an overt object expression. To this extent his book, too, supplies some evidence for mixed-transitivity behaviour in verb-coded reflexives. In the other direction - i.e. noting the reduced-transitivity status of reflexives using nominal strategies - Edmonson (1978:647) presents 'some evidence that despite encoding traits of a transitive verb, sentences containing reflexives treat such sentences syntactically as if they were intransitive', citing the fact that in Jacaltec, where relativization is achieved by the NP-like argument $s$ - $b a$ 'his/her self', relative clauses with deleted subjects fail to add the suffix $-n(i)$ to verbs, which is otherwise added to the verbs of relativized
} 
Though Faltz's monograph only mentions reciprocals in passing, similar claims have recently been made more specifically for reciprocals by König and Kokutani (2006):

"The assumption that the reciprocal affixes [...] reduce the valency (or arity) of a transitive predicate and result in the derivation of intransitive predicates with specific restrictions on their subjects is hardly controversial"

\subsection{Previous work on transitivity and reflexive/reciprocal coding strategy in Australian languages}

With regard to Australian languages, the influential survey of Australian languages in Dixon (1980) focussed on intransitivizing strategies, probably reflecting the overall preference for Australian languages to use verb-marking to encode reflexivity and reciprocity: 'Reflexive and reciprocal verbs occur only in intransitive constructions the single core NP is in S function and involves a noun in absolutive and/or a pronoun in nominative case' (Dixon 1980:433). Another survey of Australian languages (Yallop 1982:120) briefly mentions the intransitivizing effects of reflexive/reciprocal derivations in Alyawarr. Blake (1987:57), a detailed typological survey of morphosyntax in Australian languages, mentions both the intransitivizing and transitive construction types, but his only reference to problems of mixed transitivity is to point out that, in Yalarnnga, instrument phrases continue to use the instrumental/ergative case even when the subject NP receives the nominative (S) case in reflexive/reciprocal constructions; we return to this point in $\S 4.1 .5$.

The expanded and updated survey in Dixon (2002:320) gives a more nuanced characterization along lines broadly compatible with Faltz's generalization, pointing out that Australian languages use intransitive constructions when a verbal derivational affix is involved, but if the language uses a special reflexive/reciprocal pronominal element, the construction may remain transitive. He also notes (2002:320), though, that where a reflexive/reciprocal pronoun is involved, '[i]n some languages the reflexive/reciprocal construction remains transitive but in others it becomes 
intransitive', citing Nyiyaparli, Wambaya and Yanyuwa as examples (ibid:323-4) and pointing out the need for further study on the topic.

Recently two Australianists have raised the issue of mixed transitivity in reflexive and/or reciprocal constructions, though in neither case has this work been published. Dench (MS) surveys similar problems of mixed transitivity in reflexive constructions in languages of the Pilbara region. Among other findings, he notes that in Nyiyaparli, which is morphologically ergative and marks reflexives by an anaphor bound to the verb, that 'despite the fact that subjects occur in the nominative (S) case, inalienable instruments, part predicates on the subject, appear with an ergative case suffix' (p. 7). Gaby (2001), also unpublished, refers to a number of the phenomena that we bring together here, looking both at reflexive and at reciprocal constructions.

\subsection{Valency mismatches in the formal literature}

A number of formally-oriented researchers have wrestled with the question of whether reflexive and reciprocal constructions with base transitive verbs have one or two arguments, proposing a range of formal treatments which essentially posit two arguments at one level of structure, but only one at another. We discuss some of this work here, not with the intention of deciding between formal analyses, but as a way of introducing other valency-mismatch phenomena in reflexives and reciprocals, particularly in Romance, Bantu and Austronesian, that have been discussed in the literature.

Within the relational grammar literature, Rosen (1981) and a number of subsequent scholars have tried to reconcile the appearance of overt object clitic slots in French and Italian reflexive/reciprocals with the use of the 'be' auxiliary, normally associated with intransitive (more specificially, with unaccusative) constructions. The essence of their solution has been to posit a derivational history which, by having different sets of grammatical roles at different points in the derivation, allows the selection of both transitive and intransitive characteristics in the resultant structure. As summarized in Loporcaro (MS, p. 7, fn 11), the selection of 'be' auxiliaries in French, Italian etc. 'follows [from] the theory of reflexives outlined in Rosen (1981[1988], 1982). Romance reflexives are defined by the fact that their final subject also bears the 2 relation at some stratum. This multi-attachment is then resolved $(1,2->1)$ before the 
final stratum, a process that correlates with the occurrence of the clitic si.' (See also La Fauci 1988:83; Loporcaro 1998:48).

Burzio's (1986) Government-and-Binding theory analysis is similar conceptually, if not in the detail. For Burzio, the use of the 'be' auxiliary is conditioned by the existence of a (particular type of) binding relation between the subject and a 'nominal contiguous to the verb' (namely, a clitic associated with the verb or an object NP) (p. 56). Unaccusative intransitive verbs require the 'be' auxiliary since their subject is base-generated in the direct object position and subsequently raised to subject, creating a binding relation between the NP in surface subject position and the trace remaining in object position. Reflexive/reciprocal constructions also require the 'be' auxiliary since a (different type of) binding relation exists between the antecedent subject and the reflexive/reciprocal object clitic (p. 57).

Within the LFG tradition there have been several types of solution, often drawing on a level of a-structure, i.e. argument structure, an intermediate stage in the mapping between thematic roles and syntactic functions, to broker the linkage of two thematic roles to a single subject argument at f-structure. Mchombo (1991), in his account of Chichewa reciprocals, which mark reciprocity by verbal affix and reduce the valence of base transitive verbs to one, proposes that there are two arguments (corresponding to agent and patient) present in a-structure but only one in f-structure, while Alsina (1996:116-126), returning to the problem of auxiliary selection in Italian, uses the notion of 'a-structure binding' for situations where 'two co-linked arguments map onto the same grammatical function ... and therefore correspond to a single semantic participant'. ${ }^{15}$ A further LFG-based treatment is Hurst's (2003) analysis of reciprocals in Malagasy, where he posits that both subjects and objects are present in the f-structure (and the a-structure), but not in the c-structure.

Although such formal approaches address the many-to-one correspondence that can arise in reciprocal constructions between semantic participants on the one hand and syntactic arguments on the other, they all assume that reciprocal clauses are, in 'surface' syntactic terms, either transitive (having two syntactic arguments) or intransitive (having a single syntactic argument). In this paper, however, we show that

\footnotetext{
${ }^{15}$ In fact, semantically this works better for reflexives than reciprocals, since whereas reflexives involve an argument acting upon itself, reciprocals involve members of a set (the argument) acting on other members of the set. Along with Alsina and others, we ignore this problem here.
} 
languages can frequently show mixed transitivity effects just in reciprocal constructions, making it difficult to determine even on syntactic grounds whether a reciprocal construction is transitive or intransitive. While such mixed transitivity effects are clearly attributable to the competing motivations in reciprocal constructions of the low distinguishability of subject and object on the one hand, and the clear presence of multiple semantic participants on the other, they raise some important challenges for formal syntactic analyses that generally treat transitivity as a clausal property. If typologists need to decide whether clauses are either transitive or intransitive, what are they to do with constructions that show properties of both?

The goal of this paper is not to develop or test particular formal analyses of mixed transitivity phenomena in reciprocals. Rather, our goals are: firstly to describe the range of variation languages exhibit in their resolution of these competing motivations as they map reciprocal semantics onto clausal structures; secondly to expand our typology of how these conflicts are played out; and thirdly, to stimulate more research into the morphosyntactic behaviours of reciprocal constructions cross-linguistically.

\subsection{Discourse transitivity and the 'middle' construal}

Whereas the formal accounts summarized in the previous section motivate mixedtransitivity behaviour by appealing to different levels of syntactic representation, there is an alternative approach to explaining the mixed behaviour of reciprocals and reflexives within the functionalist and cognitive traditions, appealing to the relative indistinguishability of their participants, which locates such constructions in an intermediate position between prototypical transitive and prototypical intransitive construction types.

In their classic treatment of transitivity as a gradient phenomenon, Hopper \& Thompson (1980) take the distinguishability of subject and object as one parameter contributing to full transitivity. Their influential survey includes a brief remark on reflexives (1980:277-8) which

'in many languages have properties which can be explained by appealing to their intermediate status between one-argument and two-argument clauses: compared with one-argument clauses, they may be more Transitive [e.g. in having reflexive object clitics in Spanish - EGN]; compared with two- 
argument clauses, they typically display features associated with lower Transitivity.'

However, apart from a brief mention of the Indonesian prefix ber-, associated generally with intransitive constructions and also with some reciprocals and reflexives, they do not consider reciprocal data at all.

Kemmer (1993) takes up Hopper \& Thompson's point about the low distinguishability of subject and object in reflexives, and examines in more general terms the phenomenon of 'middle' constructions, under which she subsumes reflexives, self-benefactives, 'naturally reciprocal events' and a range of other event types. She accounts for the variable transitivity of such constructions crosslinguistically in terms of alternate event construals. In basic transitives, which we illustrate here diagramatically with Figure 1, subject and object are clearly distinct arguments.

John loves Mary.

Figure 1: basic transitive construal:

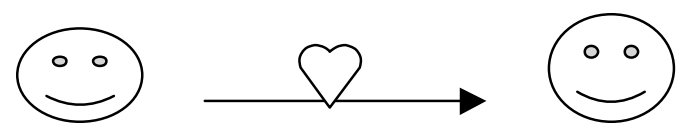

With reciprocals, on the other hand, there are two alternate construals available to speakers and the grammars they forge. The first, illustrated in (5), is effectively an overlay of two transitive construals, one upon the other, i.e. 'John loves Mary' and 'Mary loves John'; in each of the two relations, the two participants are clearly distinct. Note that in this construction, in contradistinction to standard constructions in which a unique mapping of thematic roles onto argument positions is assumed, each reciprocating argument is simultaneously linked to two thematic roles: the conjoined NP 'John and Mary' and the reciprocal expression 'each other' must each be linked to 
the dual roles of lover and lovee, or agent and patient, etc. (depending on the inventory of thematic roles being used).

(5) John and Mary love each other.

Figure 2: Overlaid transitive construal:

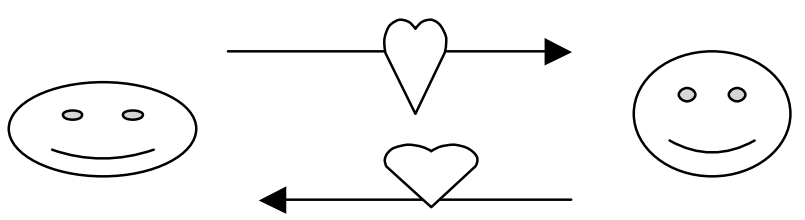

An alternative 'middle' construal unites the participant set in a single actant, and then sees the relevant predication being made, in both directions as it were, across this conjoint participant set. This is illustrated in Figure 3, and corresponds to Faltz's 'intransitive clause structure':

Figure 3: Middle conceptualization of reciprocal:

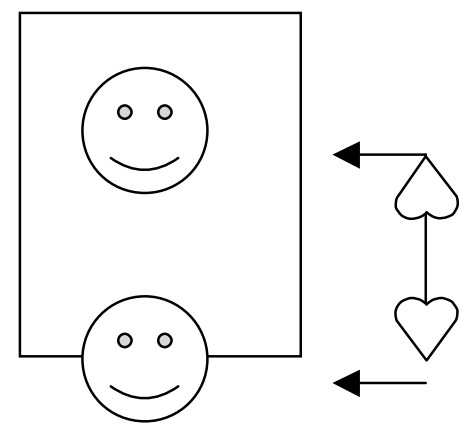

Kemmer's account shares important features with our own: in particular, its insistence on an intransitive-like semantic representation as at least one component in 
the meaning of reciprocals, a point not generally made in the formal semantic literature on reciprocals. It also seeks to integrate a number of phenomena in different languages by appealing to the playing out of - and conflict between - a single set of semantic principles across languages. Finally, it has the advantage of giving a unified explanation for both reflexive and reciprocal constructions.

However, it does not try to account explicitly for the fact that reciprocals give mixed - as opposed to intermediate - signs of valence and/or transitivity. It is conspicuous that some characteristics of lowered discourse transitivity, such as the assignment of oblique case marking or adpositions to the second argument position of transitive verbs, do not appear to be found in reciprocal constructions crosslinguistically. Although Kemmer (1993) does not discuss this issue, it is likely that it reflects a view which motivates structures in terms of a single construal in a given language, rather than, as we are proposing, seeing different predicates of a complex semantic representation motivating different parts of the structure.

\section{Languages with consistent alignment of valency}

In this section, before passing to the various mixed strategies that form the main subject of this paper $(\S 4,5)$, we illustrate the existence of languages in which reciprocals either straightforwardly conserve their valency $(\$ 3.1)$, or straightforwardly decrease it (\$3.2) ${ }^{16}$ In this and the ensuing discussion, we will use 'transitive behaviour/properties' as a shorthand for any grammatical phenomena associated prototypically (in the language in question) with bivalent clauses, and 'intransitive behaviour/properties' for those typically associated with monovalent clauses. Transitive properties, for example, might include having two overt arguments; having

\footnotetext{
${ }^{16}$ Some languages appear to have two alternative strategies available, though it would be going beyond the data we have to say that either constituted a 'clean' strategy. Balinese (Arka in prep.) is a clear Austronesian example, and Marrithiyel (Green 1989: 120) is a less clear Australian one. Interestingly, in both languages the intransitive strategy is associated with 'simultaneous reciprocity' while the transitive strategy is associated with 'sequential reciprocity'. In Balinese the intransitive strategy uses the prefix $m a$ - as a middle-voice construction, along with the use of just one overt actant, while the transitive strategy uses undergoer-voice on the verb and a free reciprocal marker saling. In Marrithiyel the sequential reciprocal fills the object (or 'goal') slot of the auxiliary with a person/number-specific object marker coreferential with the subject, while the simultaneous reciprocal uses a fixed marker in the same slot.
} 
ergative case on the subject; having verbal morphology associated with two-actant constructions (e.g. transitive pronominal affix series, other transitivity markers on the verb), and so forth. Our claim is not that such phenomena are only found in transitive clauses - in fact, our goal is to use reciprocal clauses to debunk this view - but it is nonetheless useful to have a single dimension (transitive vs intransitive) in terms of which a number of distinct grammatical traits can be sensibly characterized.

\subsection{Valency conserving strategies ${ }^{17}$}

Languages employing these strategies normally replace one of the arguments ${ }^{18}$ with some sort of reciprocal marker without changing the clause's argument structure in any way. We exemplify initially from English, using non-reciprocal / reciprocal pairs in which 'each other' replaces the non-subject argument, and the participants are encoded in a conjoined subject NP (6-8): ${ }^{19}$

(6a) Mary chased the elf around the park.

(6b) Mary and the elf chased each other around the park.

(7a) Mary called out to the elf.

(7b) Mary and the elf called out to each other.

(8a) Mary threw stones at the elf.

\footnotetext{
${ }^{17}$ We use the terms 'valency-conserving' and 'valency-reducing' in a general sense to refer to the situation in which original valence is maintained (whether it be divalent or trivalent), and the situation in which the original valence is reduced, respectively. In this section we focus particularly on reciprocal constructions formed from bivalent, particularly transitive clauses. We hold off the discussion of reciprocal constructions in trivalent clauses until $§ 5$.

${ }^{18}$ In standard transitives it appears to be universal that it is the object that is replaced by the reciprocal marker, never the subject. The commonest explanation given for this within the generative literature derives this from the need for the antecedent to c-command the anaphor, though there are alternative explanations in terms of thematic hierarchies. In some languages it is also possible for the reciprocating arguments to be two non-subjects, e.g. 'I introduced John and Mary to one another'; in which case the reciprocal expression always replaces the oblique argument. It is generally the case that the possibility of both arguments being non-subjects is limited to languages that do not encode the reciprocal relation on the verb, but use free expressions.

${ }^{19}$ English each other is odd, for a NP, in lacking any noun within it. Nonetheless, standard grammars of English typically refer to it as a 'reciprocal pronoun' (Huddleston \& Pullum 2002:1499; Quirk \& Greenbaum 1973:105), though Jespersen (1933:112) implies some (undiscussed) doubt through his formulation 'so-called reciprocal pronoun'.
} 
(8b) Mary and the elf threw stones at each other.

A comparable treatment from a language using case can be illustrated with Russian, in which the second word of the binomial expression drug drug-CASE bears the case appropriate to the reciprocated argument (the first element is invariant, remaining in the nominative). Should the verb govern a preposition, this is placed between the two elements of the binomial expression.

(9a) On vide-l ego.

RUS 3sgNOM see-PST 3sg.masc:ACC

'He saw him.' ${ }^{20}$

(9b) Oni vide-l-i drug drug-a.

RUS 3pINOM see-PST-PL other other-ACC

'They saw each other.'

(10a) On nadeetsja na nej.

RUS 3sgNOM rely.on.3sg on her-ACC

'He relies on her.' [verb subcategorizes for preposition na plus accusative]

(10b) Oni nadejutsja drug na druga.

RUS 3plNOM rely.on.3pl other on other-ACC

'They rely on each other.' (Nedjalkov 1991) [verb subcategorizes for prep.]

(11a) On pomoga-l- $\phi \quad$ eти.

RUS 3sgNOM help-PST-3sgMasc him-DAT

'He helped him.' [verb subcategorizes for DAT]

(11b) Oni pomoga-l-i drug drug-u.

RUS 3pINOM help-PST-3pl other other-DAT

'They helped each other.' [verb subcategorizes for DAT]

\footnotetext{
${ }^{20}$ The Russian reciprocal examples are from Nedjalkov (1991); the non-reciprocal examples have been constructed by us to illustrate the base structures.
} 
There are also languages using reflexive/reciprocal clitic pronouns, which still maintain distinct case forms of the clitic. Bulgarian (12) is one example, employing the form se when the reciprocated argument is the object of a transitive verb, but the dative form $s i$ if the verb is semi-transitive. ${ }^{21}$

(12a) Zabravix-me se.

BUL forgot-1.pl RR.ACC

'We forgot each other.'

(12b) Bratja-ta

BUL brothers-ART si govorjat.

RR.DAT speak

'The brothers are talking to each other.'

Languages differ, of course, in how noun-like or NP-like the reciprocal marker is. In Russian the second element resembles a standard noun (and indeed is largely parallel in its morphological behaviour to its etymological doublet drug 'friend', except that it lacks any plural form). In other languages, the noun-like nature of the reciprocal marker is clear from other tests. For example in Welsh (King 1993:103), where it derives from the word gilydd 'fellow', it exactly parallels nouns in having mutating possessed forms, with the result that there are different forms for first, second and third person (and singular and plural) reciprocal nouns. An example is given in (13).

(13) Naethon nhw gerdded yn syth heibio i'w gilydd. WEL aux.3pl.pst 3pl walk in straight past to $3 \mathrm{pl}$ fellow 'They walked straight past each other.'

\footnotetext{
${ }^{21}$ Czech is another example (Geniusiene 1987:255). For further details on Czech see Atsarkina (1963:90) and Leonovicheva (1962:158-9), and on Bulgarian see Fiedler (1972), Georgiev (1979:372) and Norman (1972:80-83).
} 
The reciprocal form jnan in Hausa, etymologically 'body', displays similar properties in having specific possessed forms ranging across all person/number possibilities (Newman 2000:530).

Regardless of the exact nature of the nominal reciprocal expression in the examples we have considered - special binomial expression in English and Russian, clitic pronoun in Bulgarian and Czech, or noun in Welsh and Hausa - in each case the construction of a reciprocal clause leaves argument structure completely unaffected, with the reciprocal expression simply filling the lower argument slot on the thematic hierarchy.

Reciprocal constructions in a number of Australian languages resemble the situations just described. Indeed, the employment of ergative case, an exquisite instrument for measuring transitivity, often provides extra evidence that the argument structure is undisturbed by reciprocal formation. We consider two examples here: Warluwarra, where the reciprocal marker is a free pronoun, and Warlpiri, where it is a clitic occupying the object slot.

In Warluwarra (Breen forthcoming:918-919) there is a set of special reflexive/reciprocal pronouns derived by adding $-w a \sim-a a$ in the singular, and $-b a$ in the dual and plural, to the base. ${ }^{22}$ (Unfortunately the grammar does not discuss the question of what case value these have, though the analysis seems to implicitly regard them as accusatives.) In reciprocal constructions this can replace the reciprocated argument slot, as illustrated in (14); importantly, the subject argument remains in the ergative, evidence that the clause as a whole remains transitive.

\footnotetext{
${ }^{22}$ Many of the languages we draw on in this paper use a single 'reflexive/reciprocal' form, and much of the discussion of this topic in particular sources uses 'reflexive' as a shorthand to cover 'reflexive/reciprocal', and glosses that reflect this. We avoid this use and consistently gloss such forms as RR. For each of these languages the question arises whether reflexives and reciprocals are treated the same by the grammar in all ways. Many of our sources assume they behave identically, without giving careful justification, and in any case we will generally bracket out examples of reflexives so as to maintain our focus on reciprocals. We will only comment on the behaviour of reflexives where the source, or subsequent information obtained from the grammarian, gives evidence of relevant morphosyntactic differences between the constructions.
} 
(14) Warrawurla-wiya-gu wulaba danmarna. ${ }^{23}$

WLW dog-DU-ERG 3duRR bite:PST

'The two dogs bit one another.' (Breen forthcoming:919)

For Warluwarra, as for so many other Australian languages, we only have one description, based on last-ditch salvage work with now-dead speakers, and we cannot explore multiple lines of argumentation to see whether reciprocal clauses are, in fact, transitive using every possible test. In order to assemble a more thorough case, therefore, we now pass to Warlpiri, by far the best-described Australian language. As we shall see, Warlpiri furnishes us with many distinct lines of evidence, all clearly demonstrating the transitive status of reciprocal clauses.

The method of expressing reciprocals in Warlpiri is to use a reflexive/reciprocal pronominal clitic -nyanu that occupies the object position: ${ }^{24}$
'where one of these arguments [of a transitive verb - EGN] anaphorically binds the other, the binder is the ergative argument, and the anaphor is the absolutive argument (represented only by the anaphoric clitic -nyanu 'reflexive/reciprocal'...) occupying non-subject ${ }^{25}$ position within the auxiliary' (Hale, Laughren \& Simpson 1995:14361437)

\footnotetext{
${ }^{23}$ Our sources on Australian languages use a variety of orthographies, with older sources often using specific phonetic symbols, but more recent sources using practical orthographies that employ digraphs for certain points of articulation. In general we have modified orthographies in the sources towards the current conventions used in practical orthographies, except that we have left untouched the (generally arbitrary) selection of voiceless vs voiced graphemes, since in most Australian languages there is no phonemic voicing distinction. The graphemes that are relevant to this paper are: $\mathrm{r}[\iota], \mathrm{rr}[\mathrm{r}], \mathrm{rt} \sim \mathrm{rd}$ [d], rd [r in Warlpiri only), rn [n], th dh [ț ]), nh [n], ng [g], ny or nj (Dalabon only) [n], h [?]. Along with the variant orthographies employed in transcription, there are often alternate spellings of Australian language names. Where practicable, we have selected the spelling preferred by the relevant speech community and used it consistently throughout the paper.

${ }^{24}$ Except where the subject is first person singular, or the clause is imperative with a second person subject, in which case the regular first or second person object forms are used, respectively.

${ }^{25}$ Hale et al (1995) use the term 'non-subject' to cover object, indirect object and some other benefactive-like functions of this slot.
} 
A comparison of the straightforward transitive clause in (15a) and its reciprocal counterpart in (15b) indicate that not only do reciprocal clauses have an overt exponent of the object in the auxiliary (-nyanu in the regular object position), but the subject of reciprocals continues to take ergative marking, just as in Warluwarra:

$\begin{array}{llll}\text { (15a) Ngarrka-jarra-rlu } & \text { ka-pala-jana } & \text { maliki-patu } & \text { paka-rni. } \\ \text { WLP man-DU-ERG } & \text { IMPF-3duSUBJ-3plNonSUBJ } & \text { dog-PAUC } & \text { strike-NPST }\end{array}$

'The (two) men are striking (killing) the dogs.'

\section{(15b) Ngarrka-jarra-rlu ka-pala-nyanu paka-rni. \\ WLP man-DU-ERG IMPF-3duSUBJ-RR strike-NPST}

'The (two) men are striking themselves / each other.' (Hale, Laughren \&

Simpson 1995:1437)

There are five pieces of additional evidence that the valency of the clause is maintained unchanged in Warlpiri reciprocal constructions.

Firstly, secondary predicates in Warlpiri are linked, through case agreement, to the arguments they modify: they take the ergative if they modify a transitive subject argument, and the absolutive (morphologically zero) if they modify an intransitive subject or object argument (Laughren 1992). ${ }^{26}$ Reciprocal clauses in Warlpiri may have secondary predicates or complements linked to either subject or object; (16a) illustrates a secondary predicate linked to the transitive subject (ngati-nyanu-jinta 'of the same mother') and taking the ergative, while (16b) illustrates a complement NP linked to the object, and taking the absolutive. (16b) further shows that, even though there can be no overt $N P$ exponent of the object position in reciprocals (only the clitic -nyanu in the auxiliary), there is nonetheless an object position to which secondary predicates can be linked. Finally, the manner expression kulu 'in anger' in (16a), though not strictly speaking predicated over the subject, since it has scope over the

\footnotetext{
${ }^{26}$ For similar examples of ergative-marked secondary predicates linked to the subject in two dialects of the Western Desert language, spoken to the west and south of Warlpiri, see Marsh (1992:81) on Martu Wangka and Goddard (1983:127) on Yankunytjatjara.
} 
whole clause, nonetheless provides further evidence for the transitive status of the clause by taking an ergative suffix.

(16a) Kurdu-jarra-rlu kuja-ka-pala-nyanu paka-rni kulu-ngku

WLP child-DU-ERG REL-PR-3duSUBJ-RR hit-NPST in.anger-ERG

\section{ngati-nyanu-jinta-rlu ...}

mother-POSS-one-ERG

'When two children of the same mother have a fight and hit each other ...' [Laughren et. al. (forthcoming)]

(16b) Pintipuyu-rlu ka-lu-nyanu ngarri-rni kunmarnu.

WLP Pintupi-ERG PR-3plSUBJ-RR call-PR [term](ABS)

'Pintupis call each other Kunmarnu.'

Secondly - really a subtype of the secondary predicate test - expressions of accompaniment or instrument, formed by adding an adnominal proprietive case to the instrument NP, are linked to the subject by an ergative case in transitive clauses, but not in intransitives. In reciprocal clauses, such expressions take an outer ergative, just like in standard transitive clauses:

(17) Kulu,ngulaji yangka kuja=ka-pala-nyanu yapa-jarra-rlu WLP fight DEM DEM REL=PR-3duSUBJ-RR person-DU-ERG

paka-rni watiya-kurlu-rlu manukarli-jarra-rlu luwa-rni
hit-PR stick-PROP-ERG and boomerang-DU ${ }^{27}$-ERG hit-PR
jarnku manuyangka kuja=ka-pala-nyanu yapa-jarra-rlu

\footnotetext{
${ }^{27}$ The suffix -jarra in Warlpiri is normally a dual marker, but in other languages nearby (notably Pitjantjatjara, where it appears in the language name in a different orthographic guise) it has developed a proprietive meaning, and according to Jane Simpson (email, 16/2/2004) it appears to be used in this example with a proprietive meaning on this word.
} 
separately and DEM REL=PR-3duSUBJ-RR person-DU-ERG

panti-rni rdaka-jarra-rlu...

punch-PR hand-DU-ERG

'Kulu is like when two people hit each other with sticks or hurl boomerangs at each other or when two people punch each other ...'

[Laughren et. al. (forthcoming)]

Thirdly, there are strict constraints on the use of the ergative case with instruments in Warlpiri: unlike in some other Australian languages (see $\$ 4.2$ below), in Warlpiri, the instrumental use of the ergative ${ }^{28}$ is only possible in transitive clauses (cf Hale 1968:4, Nash 1986:35, 227, Simpson 1991:247). There is clear attestation of this use in reciprocal (and the structurally identical reflexive) clauses, further evidence that they are transitive:

(18) Karntawarra-rlu=rlupa-nyanu mapa-ni.

WLP ochre-ERG=1incSu-RR paint-PR

'Let's paint each other / ourselves with yellow ochre.'

(Hale, 1959 field notes)

Fourthly, there is also case linkage in Warlpiri between body parts and their wholes, such that the term for the part agrees in case with the (overt or covert) exponent of the whole. Body parts in reciprocals can either take the ergative case, agreeing with the transitive subject (rdakajarrarlu 'hands' in (17) is an example), or the absolutive case, agreeing with the object (such as wanarrijarra 'thighs' in (19)): the choice depends on whether the whole is functioning as agent or patient in the focussed-on subevent of the reciprocal act, i.e. '(subject I agent) strike (with) the hand' vs 'spear (object I patient) (in) the thigh'.

\footnotetext{
${ }^{28}$ Within the Australianist tradition there is some terminological variation in what to call cases that span ergative and instrumental functions, and even on whether to regard them as a single case (as is done in the Warlpirist tradition) or as two distinct cases (as Dixon 1972 does for Dyirbal). Here we adhere to the Warlpirist terminology.
} 
(19) ... manuyangka kuja=ka-pala-nyanu

WLP ... and DEM REL=PR-3duSu-RR

yapa-jarra-rlu jarnku panti-rni wanarri-jarra

person-DU-ERG separately spear-PR thigh-DU(ABS)

mirnimirni kurlarda-kurlu-rlu - kulu-ngku-ju.

equally spear-PROP-ERG fight-ERG-EUPH

'... and when two people spear each other in the thigh in a fight.' [Laughren et.

al. (forthcoming)]

Fifthly, complement clauses in Warlpiri signal whether they have a subject or an object antecedent by taking different verbal suffixes: -kurra if the antecedent is an object; and -karra plus ergative case if the antecedent is a reflexive subject (i.e. if the antecedent, being in a reflexive or reciprocal clause, is the subject that is coreferential with the clausal object). ${ }^{29}$ Complement clauses of reciprocal perception verbs can take either object-controlled forms (20a) or subject-controlled forms (20b), according to their interpretation, clearly establishing the presence of both subject and object arguments in the reciprocal clause.

(20a) Kurdu-jarra-rlu ka-pala-nyanu nya-nyi, karri-nja-kurra. WLP child-DU-ERG IMPF-3duSub-RR see-NPST stand-INF-OBJ.COMP 'The two children see each other (who are) standing.'

(20b) Kurdu-jarra-rlu ka-pala-nyanu nya-nyi, WLP child-DU-ERG IMPF-3duSub-RR see-NPST

karri-nja-karra-rlu.

stand-INF-REFL.SUBJ.COMP

\footnotetext{
${ }^{29}$ See Simpson \& Bresnan (1983) for a detailed description of the system.
} 
'The two children see each other (as they are) standing., ${ }^{, 30}$

(Hale 1982:295, also cited in Simpson 1991:165)

The Warlpiri and Warluwarra examples, then, clearly illustrate the possibility that languages will encode reciprocal constructions with exactly the same argument structure as their corresponding non-reciprocal clauses. We now turn to Australian examples representing the opposite pole - comparable to the Mundari example in (3) - where languages effect an unambiguous reduction in valence in reciprocal clauses.

\subsection{Valency reducing strategies.}

As indicated by the quote from Faltz (1985) in section $§ 2$, many languages respond to the 'equation' of subject and object arguments by fusing antecedent and reciprocator into a single argument position, reducing the clause's valency by one. Applied to a basic transitive verb, this yields an intransitive verb in the reciprocal. In this section we will only consider the situation with base transitive verbs, holding off the discussion of what happens with base ditransitives until $\S 5$.

Unambiguous reduction of valency in reciprocals is claimed for the majority of Australian languages, typically accompanied by verbal affixation. ${ }^{31}$ Two tests for valency reduction are usually employed:

(a) the overt appearance of maximally one argument

(b) the employment of a case frame, or a form of pronominal affix, associated with intransitive rather than transitive constructions. That is, instead of the nominative:accusative, ergative:absolutive or ergative:accusative case frames found in the transitive construction, there is a single NP bearing the nominative (if the

\footnotetext{
${ }^{30}$ We thank Mary Laughren for supplying these sentences, which are the reciprocal versions of the following reflexive counterpart, published in Hale (1982:295) and Simpson (1991:165):

(i) Kurdu-ngku ka-ф-nyanu nya-nyi, karri-nja-kurra.

WLP child-ERG IMPF-3sgSub-RR see-NPST stand-INF-OBJ.COMP

'The child sees himself standing.'

${ }^{31}$ Dixon (2002: 520) gives a figure of about 105 Australian languages, out of 140 surveyed, in which reciprocal constructions are encoded by verbal affix (which may or may not be the same as the reflexive) with accompanying reduction in valency, although it is possible that some of the languages in this figure may in fact exhibit mixed transitivity behaviour.
} 
language is nominative:accusative or tripartite) or absolutive (if the language has an ergative:absolutive case system). ${ }^{32}$

Thus in Ngiyambaa, where subjects of transitive clauses take the ergative case (21), the subjects of the corresponding reciprocals (encoded by verbal affix) take the nominative (22); Dyirbal (23) displays a comparable pattern.

Mirri-gu yugi gadha-ra.

NGI dog-ERG dingo(ACC) bite-PRES

'The dogs are biting the dingos.' (Donaldson 1980:168)

(22) Mirri-bula: gadha-la-nha.

NGI dog-DU:NOM bite-REC-PRES

'The two dogs are biting one another.' (Donaldson 1980:168)

(23a) Bayi yara ba-nggu-n jugumbi-ru bara-n.

DYI DEM:ACC:I man(ACC) DEM-ERG-II woman-ERG punch-NF

'The woman punched the man.' (Dixon 1972:93)

(23b) Bayi yara-garra bala-n

\footnotetext{
${ }^{32}$ In tripartite systems there are distinct cases (generally glossed ergative, nominative and accusative) for A, S and $\mathrm{O}$ roles. There has been considerable debate in the Australianist literature about the proper analysis of so-called 'split' systems, where some nominals (prototypically inanimate nouns) split forms on an ergative:absolutive basis, while others (prototypically first and second person pronouns) split them on a nominative:accusative basis. We follow Goddard (1982) and Mel'cuk (1979) in recognizing a single case value right through the nominal word class even where some stems show neutralizations. On this position far more Australian languages have tripartite systems than on a more surface-based analysis in terms of 'split nominative/accusative vs ergative/absolutive case marking'. Our glossing in this paper reflects this tripartite analysis, so that some of our case glosses don't correspond to those in the original. In some languages however (e.g. Warlpiri) the fact that all members of the nominal class (including pronouns) split on an ergative:absolutive basis allows us to retain the ergative:absolutive glossing system. Note that the term 'nominative' will have a different meaning in tripartite systems (where it is confined to intransitive clauses) to what it has in nominative:accusative systems (where it can mark the subject of either intransitive or transitive clauses). A further analytic problem that arises in tripartite languages is that of determining whether zero-marked nominals are in nominative or accusative case; this is relevant to the question of whether there are nominative:accusative (i.e. S:O) case frames in the reciprocals of some languages (see $\$ 4.1 .3$ below).
} 
DYI DEM:NOM:I man-one.of.pair(NOM) DEM:NOM-II

\author{
jugumbil-garra \\ baralbaral-nbarri-nyu. \\ woman-one.of.pair(NOM) punch:REDUP-REC-NF
}

'The man and the woman punched one another.' (Dixon 1972:93)

In both of these languages, the reciprocal is marked by verbal coding. However, there are also languages that use other coding methods for reciprocals, but nonetheless show a reduction in valence. In Gumbaynggir (Eades 1979:315), reciprocals do not take any verbal marking, being encoded simply by a change in case frame, from ergative:accusative (24a) to nominative (24b), plus the use of the reciprocal particle galagala.

(24a) Ngiya:la bu:rwaw ngi:na.

GUM1pl.inc.ERG paint:FUT 2sg.ACC

'We will paint you.'

(24b) Ngiya: $\quad$ galagala bu:rwaw .

GUM 1pl.inc.NOM PART paint:FUT

'We will paint each other.'

Karrwa (Garawa) (Furby \& Furby 1977:62) uses a single free-reciprocal/reflexive pronoun without other constructional coding (25a). This has a special form, distinct from standard pronouns, but it is difficult to say what its case is since it does not participate in a case paradigm. However, evidence from other nominals that may be apposed to it in the same clause suggest it takes the nominative rather than the ergative/instrumental: Mushin (2000) gives example (25b) in which the nominal kurrukurru 'big mob', seemingly forming a discontinuous NP with the reciprocal pronoun and therefore presumably in the same case, takes the zero form characteristic of the nominative (in this example the subject is grammatically singular but semantically plural). 


(25a) jala daba yalu-ngk=i.
KAR then hit 3pl-RR=PST
'then they hit each other.'

(25b) Dabana-ngk=i nanaba kurrukurru.

KAR fight 3 sg-RR=PST there big.mob(NOM)

'Big mobs of people fought each other there.'

The encoding of reflexive/reciprocal constructions with a single pronoun or pronominal affix is also found in two languages that neighbour Karrwa: the closelyrelated Wanyi (Laughren 2001), ${ }^{33}$ which likewise uses a single freereciprocal/reflexive pronoun without other constructional coding, and Yanyuwa, just to the north of Karrwa, which is related to Warluwarra (see example (14) above), but which has developed bound pronominal prefixes, probably under areal pressure from the head-marking, prefixing languages to its immediate north. In Yanyuwa, reflexive/reciprocal clauses formed from transitive verbs have a single pronominal prefix, with a special reflexive/reciprocal form, typically derived by adding $-m b a^{34}$ or -inyamba to the regular intransitive form, with a few irregularities: cf 1 sg intransitive subject arna-, 1sg RR arna-mba; 3 feminine intransitive subject $i$ - ( ilha- ), 3 fem sg RR inyamba (Kirton \& Charlie 1996:91 gives the full set of forms). Free NP expressions in reflexive/reciprocal clauses in Yanyuwa take the nominative rather than the ergative case (Kirton \& Charlie 1996:123).

A similar construction to that in Karrwa and Wanyi is found in the South Australian language Yaraldi (Cerin 1994): here again the verb is left in its normal

\footnotetext{
${ }^{33}$ As in Karrwa, the determination of case on the reflexive/reciprocal pronoun in Wanyi is tricky, and depends on finding examples with apposed nominals, but made trickier by the fact that for nouns the ergative is signalled by vowel-length, which is rather difficult to hear in Wanyi. Laughren (2001) claimed that subject nouns in reflexive/reciprocal constructions lacked the vowel lengthening characteristic of ergative marking in regular transitive clauses, and that therefore reflexive/reciprocal constructions involved case reassignment to their subjects, from ergative to nominative. However, she has since rechecked her transcriptions of this data, as well as obtaining examples with demonstratives where the ergative suffix (-ni) is clearer, and her current position (email to NE, 5/5/2004) is that subjects of reflexive/reciprocals retain the ergative marking found in straight transitives.

${ }^{34}$ This form is probably cognate with the suffix $-b a \sim-a$ found on free reflexive/reciprocal pronouns in Warluwarra; cf Dixon (2002:324).
} 
(transitive) form, while reflexive/reciprocal pronouns are based on the nominative (intransitive subject) pronoun form:

(26) wony=angk-inang ngaiyu-wol-el

YAR then=3duNOM-RECIP be.angry.at-INCH-TAM

'then the two (women) become angry at each other...'

(Cerin 1994:80)

In a non-reciprocal construction with the same verb the form of the subject pronoun would be anggul (3duERG) (Cerin 1994:53).

Most descriptions of reciprocals with valency reduction unfortunately give no further criteria, so that we cannot eliminate the possibility that other more sensitive measures might detect transitive behaviour, of the type we will exemplify in $\S 4$. However we can use Wambaya (Nordlinger 1998) and Yukulta (Keen 1983) as two examples of languages where a wider range of criteria all point to intransitive behaviour in reciprocal clauses.

3.2.1 Wambaya. Wambaya is a language of the Barkly tablelands region whose traditional country adjoins that of Karrwa and Wanyi. It encodes reflexive/reciprocal constructions with a clitic -ngg- (Nordlinger 1998), apparently cognate with the Karrwa/Wanyi form discussed above. This reflexive/reciprocal marker appears in the object position in the auxiliary, giving the appearance of a reflexive/reciprocal object pronoun similar to -nyanu in Warlpiri (e.g. (15b) above). The examples below contrast a regular transitive clause (27a) with a corresponding reciprocal clause (27b).

(27a) Ngajbi irri-ng-a.

WMB see $3 p l A / S-1 O b j-N F$

'They saw me.'

(27b) Ngajbi irri-ngg-a.

WMB see 3plA/S-RR-NF

'They saw each other.' 
At first blush, it may appear that Wambaya reflexive/reciprocal clauses remain transitive, similar to their Warlpiri counterparts, especially since third singular subject bound pronouns - which are the only bound pronouns that distinguish transitive and intransitive subject forms - must appear in their transitive form in such constructions (with reflexive function) (Nordlinger 1998:141):

(28a) Gulugbi g-a.

WMB sleep 3sgS-PST

'He slept.'

(28b) Ngajbi gini-ng-a.

WMB see 3sgmA-1Obj-NF

'He saw me.'

(28c) Ngajbi gini-ngg-a. (*gi-ngg-a)

WMB see 3sgmA-RR-NF

'He saw himself.'

However, evidence from a variety of other morphosyntactic sources shows these reflexive/reciprocal constructions to in fact be intransitive. Firstly, an external subject NP must appear in the nominative case in reflexive/reciprocal constructions, rather than the ergative, as shown by the contrast between (29a) and (29b).

(29a) Daguma irri-ng-a alangmiminyi-ni.

WMB hit 3plA-1Obj-NF children.I-ERG/LOC

'The children hit me.'

(29b) Daguma irri-ngg-a alangmiminji(*-ni).

WMB hit 3plA-RR-NF children.I(NOM) (*-ERG/LOC)

'The children hit themselves / each other.'

Note, however, that while the ergative/instrumental case is not possible on the subject $\mathrm{NP}$ in these constructions, it is possible in its other role of marking instrument as 
shown in (30). Since this is also possible with some base intransitive verbs like 'speak (in a language: INSTR)' we do not consider this a case of transitivity mismatch in Wambaya (cf §4.2).

$$
\text { Alangmiminji irri-ngg-a daguma darrangu-nu. }
$$

WMB children.I(NOM) 3plA-RR-NF hit stick.IV-ERG/LOC 'The children are hitting each other with sticks.'

Furthermore, complements of reciprocalised perception verbs show subject-control (marked with ERG/LOC), as if the reciprocal verb were intransitive, rather than the expected object-control (marked with INF) that would be found in the nonreciprocalised (transitive) equivalent. Example (31a) demonstrates the use of the ERG/LOC for subject-control in a regular intransitive clause; (31b) demonstrates the use of the INF for object-control in a transitive clause with a perception verb; and (31c) shows its reciprocalised equivalent with ERG/LOC, rather than INF marking, on the controlled verb.

(31a) Ngurruwani ngurru-n mirra gili ngarli-ni.

WMB 1plinc(NOM) 1plincA/S(PR)-PROG sit here talk-ERG/LOC 'We're sitting here talking.' (Nordlinger 1998: 165)

(31b) Manku ngu-ny-u ngarl-warda ngarlana.

WMB hear 1sgA/S-2Obj-FUT talk-INF language.IV(ACC)

'I'll hear you talking language.'

$\begin{array}{lllll}\text { (31c) } & \text { Yardi } & \text { nguy-u } & \text { ngurra } & \text { ngaba } \\ \text { WMB } & \text { put } & \text { 3sgfA-FUT } & \text { 1plincOBL } & \text { THEN }\end{array}$

$\begin{array}{llll}\text { ngurru-ngg- } u & \text { manku } & \text { ngarli-ni } & \text { ngarlana. } \\ \text { 1plincA/S-RR-FUT } & \text { hear } & \text { talk-ERG/LOC } & \text { language.IV(ACC) }\end{array}$

'She'll put (the tape) on for us and then we'll hear ourselves/each other talking language.' (Nordlinger 1998: 208) 
Finally, the fact that the reflexive/reciprocal marker does not function as a reflexive/reciprocal object pronoun in Wambaya is demonstrated by the fact that it can co-occur with semi-transitive verbs, whose indirect object complement cannot be cross-referenced by an object pronoun in the auxiliary (Nordlinger 1998: 142).

(32a) Ayani ngi nganga.

WMB look.for $1 \operatorname{sg} \mathrm{A} / \mathrm{S}(\mathrm{PR}) \quad 2 \mathrm{sgOBL}$

'I'm looking for you.'

(32b) *Ayani ngi-ny-a.

WMB look.for $1 \mathrm{sgA} / \mathrm{S}-2 \mathrm{Obj}-\mathrm{NF}$

'I'm looking for you.'

(32c) Ayani ngurlu-ngg-a.

WMB look.for 1duexcA/S-RR-NF

'We're looking for each other.'

Examples (32a) and (32b) demonstrate that the indirect object of a semi-transitive verb such as ayani 'look for' cannot be cross-referenced by an object bound pronoun in the auxiliary, but must be expressed with an external dative (oblique) NP. In contrast, the corresponding reciprocalised clause contains the regular reciprocal marker $-n g g$ - in the auxiliary. If this were a reciprocalised object bound pronoun, we would have no explanation for its occurrence with semi-transitive verbs, which otherwise do not co-occur with object cross-referencing. If, on the other hand, -nggis a valency-reducing reflexive/reciprocal marker, as the above evidence suggests, these facts follow straightforwardly.

Thus Wambaya, though superficially like Warlpiri in having a secondposition auxiliary indicating subject and object positions; in replacing the free object marker with a fixed reflexive/reciprocal morpheme invariant for person; and in having distinct complementized verb forms according to whether the antecedent is 
subject or object, differs from it in reducing the transitivity in reflexive/reciprocal constructions. ${ }^{35}$

3.2.2 Yukulta. Yukulta belongs to the Tangkic family like Kayardild (§4.3.2) but differs from it typologically in a number of ways, including the fact that it has an auxiliary in second position, and has retained the original ergative case-marking system of the Tangkic family. Geographically it adjoins Karrwa and Wanyi, which in turn adjoin Wambaya; and shares significant features of morphosyntactic organization with all three of these languages, including - relevant here - a thoroughgoing reduction of transitivity in reciprocal constructions. Four distinct morphosyntactic facts point demonstrate this:

(a) the reduction in the number of overt arguments from two to one,

(b) the use of distinct transitive and intransitive forms of the auxiliary (the transitive form kanta in (33a) vs the intransitive form lingka in (33b)),

(c) the shift in subject case-marking from ergative in base transitives (33a) to nominative in reciprocals (not evident in this example but clear from other examples in Keen's grammar),

(d) instrumental adjuncts in the comitative, which take a further ergative in transitive constructions in agreement with the subject (33a), but do not have this in reciprocals (33b).

(33a) Rtangka-ya=kanta ngawu palatha, thungal-urlu-ya.

'The man hit the dog with a stick.' (Keen 1983:248, ex. 229)

(33b) Purlti-nyju-tha=lingka

wangal-kurlu

\footnotetext{
${ }^{35}$ Despite being geographically close (though not adjacent), and despite sharing many areal characteristics of the north-central Australian area, Warlpiri and Wambaya are only extremely distantly related genetically: Warlpiri is a Pama-Nyungan language (of the Ngumpin subgroup), while Wambaya is a non-Pama-Nyungan language of the so-called Mirndi group. Most of the convergences reflect historical changes in Wambaya, such as the loss of prefixing, shift to an almost exclusively suffixing typology, and development of a second-position auxiliary from a series of old inflecting verbs - see Green (1995), Nordlinger (1998), Green and Nordlinger (2004) and Harvey, Green and Nordlinger (2006) for discussion.
} 
YUK hit-REC-IND-3plS+PAST boomerang+COM

\author{
rla:-nthu-tha=lingka miyarl-urlu. \\ spear-REC-IND=3plS+PAST spear+COM \\ 'They speared one another (with spears) and hit one another with \\ boomerangs.' (Keen 1983:234, ex. 145)
}

In each of these examples, all the grammatical indicators have pointed the same way: the case marking on the arguments themselves, the form of pronominal affixes or clitics, and case marking on other NP elements agreeing with subject NPs, all signal that the reciprocal clause is intransitive. We now turn to cases where the evidence is mixed, with some grammatical indicators showing transitive behaviour, and others being associated with intransitives.

\title{
4. Mixed strategies
}

Having exemplified the many Australian languages with 'clean' strategies in reciprocal constructions, in this section we turn to the empirical core of this paper: those languages exhibiting 'mixed' transitivity properties, where the tests for transitivity contradict each other just in this construction type. As argued in $\S 2$, these languages pose a variety of interesting problems since they highlight the ambivalent nature of reciprocity with respect to argument structure.

\subsection{Case marking and core argument structure}

In languages with productive ergative:absolutive case marking, there is normally a strong correlation between the case marking of the subject and the transitivity of the verb. Transitive verbs generally have ergative subjects, and intransitive verbs generally require nominative or absolutive subjects. In a number of languages, however, reciprocal (and sometimes also reflexive) constructions are counterexamples to this generalisation: there may be only a single argument in the ergative case or, conversely, two arguments in the absolutive/nominative case.

4.1.1 Single argument, in ergative. In some Australian languages with ergativeabsolutive case marking, the reciprocal construction may be unique in allowing an 
ergative-marked subject in an otherwise intransitive clause (i.e. these languages do not otherwise allow single ergative arguments). This situation is found in Badjala (Bell 2003:131) in which reciprocal constructions have just a single syntactic argument, yet the subject may be inflected with either the (regular) nominative case (34a) or the ergative case (34b). Example (34a) has the structure of a regular intransitive clause. In example (34b), on the other hand, the reciprocal construction has the intransitive property of having only a single syntactic argument, but the transitive property of having a subject in the ergative/instrumental case.

\section{(34a) Bula bana nhaa-dhula-nj barangga. \\ BDJ 3duNOM later see-REC-INTENT morning \\ 'Those two will see each other in the morning.'}

\section{(34b) Bula-ru bayi-lda-y. \\ BDJ 3du-ERG/INSTR hit-REC-IMP \\ 'Those two hit each other.'}

Bunuba (Rumsey 2000:118) and Kuuk Thaayorre (Gaby 2006) both allow similar variation between ergative and nominative case on the single argument subjects of reciprocal clauses, as shown in (35)-(36) ${ }^{36}$. Interestingly, in Bunuba, where the same verbal form is used for both reflexives and reciprocals, there is a strong correlation between the employment of ergative marking and reciprocal interpretations: 'when the subject is non-singular, there is some tendency for ergative marking to be associated with reciprocals meanings (action upon one another) rather than reflexive (action by each upon him/herself), but the correlation is not perfect.' (Rumsey 200:119). In fact, among the examples he gives in the grammar, reciprocals allow either, but reflexives all take the nominative, so it may be possible to formulate a

\footnotetext{
${ }^{36}$ In an elicitation context, many Kuuk Thaayorre speakers strongly prefer an ergative-marked reciprocal subject NP. In natural speech, however, reciprocal subjects are often unmarked for case. The speakers questioned could not offer any intuitions as to why some reciprocal subjects received ergative case marking while others did not. Observationally, ergative marking seems more frequent in clauses where the reciprocants exhibit a high degree of intention, volition and physical control (e.g. in events of chasing, giving, fighting, etc.) as opposed to accidental or otherwise less agentive events (e.g. seeing, forgetting, etc.). This correlation is not absolute, however, and remains to be proven.
} 
general rule that only reciprocal interpretations allow the use of the ergative case; further data would be needed to test this.

(35a) Jirali gurama ganba'wurrayningarri.

BUN before man chase.3nsg.RA2(aux):RR:PST:CTV

'Olden-days people used to chase each other.'

(35b) Biyirri-ingga nyaga'wurriyni.

BUN they-ERG spear.3nsg.WU2(aux):RR:PST

'They speared each other.'

(36a) Parr_r peln ii waarin-rr.

KTH kid(NOM) 3pl(NOM) there chase-RECIP:NPST

'All the kids are chasing each other.'

(36b) Parr-an peln ii waarin-rr.

KTH kid-ERG 3pl(ERG) there chase-RECIP:NPST

'All the kids are chasing each other.' [Gaby, field notes]

In Gooniyandi, relatively closely related to Bunuba, reflexive/reciprocal clauses are anomalous in being the only clause with a single overt argument in which the ergative is employed. According to the formulation in McGregor (1990:319), the same typologically anomalous situation obtains with both reflexives and reciprocals, rather than allowing the variable realization (and tendency to associate ergative marking with reciprocals rather than reflexives) that is found in Bunuba. Finally, recall that in Wanyi (footnote 33), nominals apposed to the 'reflexive/reciprocal subject pronouns' take the ergative case.

Otherwise, constructions with a single, ergative argument are virtually unknown in Australian languages overall, and certainly in the languages we have discussed above (with the exception of Gooniyandi, where the rules for using the ergative are more complex - see McGregor 1992) these are the only constructions that permit ergative 
marking on a sole core argument (in an elicitation context ${ }^{37}$ ). Outside reciprocal and reflexive constructions, the only significant use of ergative-marking on single actants is in Bandjalang, where this is found with a small number of cognate-object verbs (Crowley 1978:107-8).

4.1.2 Single argument, in accusative (Unattested) The logical converse of the single ergative argument would be to have a single accusative argument, but we do not know of any such examples with reciprocal use. There are, however, examples with 'accidental reflexive' meaning reported for Guugu Yimidhirr (Haviland 1979:123-4), which have a single argument in the accusative (plus an instrument NP in the instrumental, but Haviland argues that this cannot be the subject), which may either be just the whole-denoting pronoun (37a) or additionally have a linked nominal denoting the part (37b):

(37a) Nganhi wagi-idhi naaybu-unh.

GYI 1sg:ACC cut-RR:PST knife-INST

'I got cut on the knife.'

(37b) Nganhi dhamal daam-adhi galga-anh .

GYI 1sg:ACC foot:ACC ${ }^{38}$ spear-RR:PST spear-INST

'I got speared in the foot, accidentally, with a spear (e.g.

it fell out of a tree and got me on the foot).'

It would be interesting to discover whether similar constructions could be found with 'accidental reciprocals' such as 'we bumped into one another'.

\footnotetext{
${ }^{37}$ In addition to its syntactic function, the Thaayorre ergative morpheme has the pragmatic function of marking 'unexpected Actors' (Gaby forthcoming). The ergative marking in (36b), however, is unambiguously syntactic, since speakers would not have allowed pragmatic ergative marking in the decontextualized elicitation setting in which these examples were collected.

${ }^{38}$ Haviland, who uses a split-case approach, glosses this as 'foot+ABS'; the form is consistent with it being either nominative or accusative (in tripartite terms) but we assume it is accusative through general principles of part-whole case agreement.
} 
4.1.3 Two Arguments, neither ergative Another logically possible mixed strategy in an ergative:absolutive language is for a reciprocal construction to have a transitive argument structure without an ergative subject. Such a construction would therefore have an overt object NP (e.g. a reciprocal marker) and a nominative or absolutive subject. We know of no ergative:absolutive language with this construction in regular 'transitive' reciprocal constructions (though see Austin (1982) who mentions a few languages that have similar phenomena with a restricted class of 'cognate object' verbs), but this situation arises in reciprocals formed from ditransitive verbs in Wambaya (31). The reciprocal marker (here encoding the source relation) requires the subject to take nominative, rather than ergative case (as discussed in §3.2.1), while the theme argument remains in the accusative case. ${ }^{39}$

$$
\text { Ngarringga wurlu-ngg-a alaji gambada wardangarri. }
$$

WMB take.from 3duA/S-RR-NF child:ACC sun:NOM moon:NOM

'The sun and the moon took each other's child.' [lit. The sun and the moon took a/the child from each other.] (Nordlinger 1998:239)

This reciprocal construction is the only Wambaya construction with a regular, overt direct object NP and a nominative subject. ${ }^{40}$

\subsection{Use of instrumental case}

In discussing Warlpiri reciprocals in $§ 3.1$, we mentioned that the marking of instruments with the (ergative)/instrumental case in Warlpiri is limited to transitive

\footnotetext{
${ }^{39}$ Though there is no given word class that makes a three-way distinction, the fact that pronominals cut the A / S / O space one way (A\&S vs O) while nominals cut it the other way (A vs S\&O) allows the establishment of a tripartite system for Wambaya, with ergative/locative, nominative and accusative cases distinguished (Nordlinger 1998). In this example and others like it, it so happens that both the S and the $\mathrm{O}$ argument have the same zero form, but replacing them with prominals would allow us to see that with the right exponents the two cases can be distinguished.

${ }^{40}$ There is one other restricted construction with two non-ergative NPs in Wambaya. This involves the verb ngarlwi 'talk' which takes a nominative subject and can also take a cognate object in the accusative case referring to the language spoken (Nordlinger 1998:184). This is clearly lexically specific, however, whereas the reflexive/reciprocal construction described above is possible with all ditransitive verbs.
} 
clauses, and that its occurrence in reciprocal constructions can be regarded as further evidence for their transitive status.

Whether instrumental case is restricted to transitive clauses varies considerably from language to language in Australia. At the one extreme are languages like Warlpiri where all clauses with instrumentals, even reflexives and reciprocals, are clearly transitive. At the other extreme are languages with no restrictions on the use of the instrumental with base intransitive verbs. Examples are Yir-Yoront (Alpher 1973:179), Bularnu (Breen 1976a), Wagaya (Breen 1976b) and Kalkatungu (Blake 1979), which permits the instrumental with intransitive verbs of speaking (cf Blake 1977:47), and Mparntwe Arrernte (Wilkins 1989:172-3) which permits the instrumental with a wide range of intransitive verbs. Obviously, in these languages, the presence of instrumental case in reciprocals cannot be used as a diagnostic of transitivity.

In some languages, however, there is a general restriction of the instrumental to base transitive clauses but, exceptionally, instrumentals are permitted in reciprocal and reflexive constructions. Such a language is Alyawarr (Yallop 1977:72), where instrumentals are normally confined to transitive clauses, but just in the case of reflexives and reciprocals, both formally intransitive by the diagnostic of there being a single overt actant in the nominative, instrumental case may be used. Though Yallop himself doesn't give any examples with instrumentals in reciprocals, (39) from the Alyawarr dictionary (Green 1992) provides an illustration. Note also that ergative/instrumental marking on secondary predicates is also possible in reciprocals, as illustrated by (40).

(39) Ampa

$$
\text { akely-rnem }
$$

atw-err-eyel

arwerle-l.

ALY child(NOM) little-PL(NOM) hit-REC-PR.CONT stick-INSTR

'The kids are hitting each other with sticks.' (Green 1992:116)

(40) Intem-antey-ang ratherr arwelth-el atw-err-eyel?

ALY always-still-Q two:NOM jealous-INSTR fight-REC-PR.CONT

'Are those two always having jealous fights?' (Green 1992:136) 
The Alyawarr data can be seen as part of a more general pattern whereby, in some languages, instrumental case is licensed by the case frame of the basic clause from which a range of valency rearrangements can be derived, since similar patterns are found in reflexives and antipassives:

In all languages an instrumental argument can be included in a transitive clause with certain classes of verbs. In some it may also be used in an underived intransitive clause... However, derived intransitives always permit an instrumental NP if this could occur in the corresponding transitive. That is, if a passive, antipassive, reflexive or reciprocal derivation acts to detransitivise a clause, the instrument NP is unaffected.' (Dixon 2002:136) ${ }^{41}$

In $\S 6.3$ we return to the question of how the conditions on use of the instrumental case can best be characterized in such languages.

\subsection{Object suppressed, but body part continues to behave as if apposed to object}

We have already encountered, with Warlpiri (\$3), the widespread pattern in Australian languages of linking body parts syntactically to NPs denoting their 'wholes'. In Warlpiri this is manifested by case linkage between part and whole, with the whole being generally regarded as the argument proper, and the part as linked to it by a sort of apposition (Hale 1981). ${ }^{42}$ In this section we describe two sorts of reciprocal construction which are a sort of converse of the 'phantom limb': the part is overt, and is treated morphosyntactically as if it were linked to a (phantom) object denoting the whole. In this section we describe two quite distinct manifestations of

\footnotetext{
${ }^{41}$ In illustration, Dixon cites this reflexive example from Murrinh-patha (Walsh 1976:407):

(i) M-e-m-njeytj nandji-marimari-re.

MuP 1sg-REFL-PAST-cutCLASSIFIER:THING-knife-INST

'I cut myself with a knife.'

The Guugu Yimidhirr sentences in (37) provide further examples with reflexives, and both Dyirbal (Dixon 1972) and Yidiny (Dixon 1976:320) include clear examples with antipassives, where the instrumental case is used despite the reassignment of case frame from ERG:ACC to NOM:DAT or NOM:LOC.

${ }^{42}$ Though this is sometimes regarded as 'possessor raising', we do not adopt this analysis since there is generally no evidence for any agnate construction in which the 'whole' is expressed as a possessor.
} 
this phenomenon: in Dalabon (\$4.3.1) it plays out as the incorporability of part nouns in a way that looks like they are linked to objects denoting their wholes, even though other aspects of the reciprocal construction pattern like intransitives with no overt object; in Kayardild (§4.3.2) it plays out through a special sort of case linkage (in the form of 'modal case') to objects that have been apparently suppressed in the reciprocal construction.

\subsubsection{Body part incorporation and Dalabon reciprocals.}

On the surface, Dalabon ${ }^{43}$ reciprocals appear to be of the valency-reducing type discussed in $\$ 3.2$. Dalabon verbs have two sets of pronominal prefixes: a monovalent set, used with intransitives (e.g. 41a), and a divalent set, used with transitives (e.g. $41 b$ ) and ditransitives ${ }^{44}$ (see $\$ 5.2$ ). For non-singular objects, an overt object clitic is generally present, as with bunu in (41b), and there is also a change in vowel quality in the subject prefix, as long as it is disyllabic, with the vowel $a$ associated with intransitives and the vowels $i, \hat{u}$ or $u$ associated with transitives. ${ }^{45}$

\section{(41a) Wawurd-ko \\ barra-h-bo-n. \\ DAL elder.brother-DYAD 3duS-ASS-go-PR}

'The two brothers are going along.'

\footnotetext{
${ }^{43}$ Dalabon examples are either from Evans et al. (2004) or from Evans (field notes).

${ }^{44}$ In ditransitives the 'object' slot agrees with the indirect object. There are also derived three place verbs built up from verbs of lower valency by the addition of one or more applicatives; the situation there is complex, but basically the object slot shows agreement with whichever argument is prototypically higher in animacy: see Evans $(1997,2003)$ for descriptions of the very similar system in Bininj Gun-wok (Mayali).

${ }^{45}$ There is also an optional ergative/instrumental marker $-y i(h)$, though the variability and complexity of its use makes it a less straightforward test to apply: it is commonest in the case of inanimates acting upon humans, but can apply right up the Silverstein scale, including on first person pronouns. It is also used with subjects of the normally intransitive verb 'say' when a quotation is present as a sort of clausal object, e.g. nahda ngey ngalng-bon, nahda njing djalng-bon, kah-yininu walwalngurru-yih 'Me, I'll go this way, and you go this way' said the lizard.' (Evans et al. 2004: 364). So far there are no examples of it being used with reflexive/reciprocal clauses, however, providing a further piece of intransitive behaviour in reflexive/reciprocals, though we shall see in $§ 5.2$ that it is sometimes used with the reciprocals of ditransitive verbs.
} 
(41b) Buпи burra-h-na-n.

DAL 3duObj 3duA-ASS-see-PR

'They $\mathrm{two}_{\mathrm{i}}$ are looking at them $\mathrm{two}_{\mathrm{j}}$ '

Reciprocal constructions are marked by a suffix - $r r$ - to the verb stem, which also indicates reflexives (Evans \& Merlan 2003); transitive verbs taking this suffix then take the monovalent prefix set. Compare the transitive form, with its divalent prefix bûla- in (42a) with the reciprocal form in (42b), which takes the monovalent prefix set:

(42a) Bûla-h-na-ng.

DAL 3plA/3Obj-ASS-see-PR

'They see him/her.' (42b) Bala-h-na-rr-un. 3plS-ASS-see-RR-PR

'They see each other.'

However, another grammatical test is harder to reconcile with viewing these clauses as simply intransitive. Verbs in Dalabon can incorporate a nominal root referring to a body part of one of the arguments. With intransitives this is a body part belonging to the intransitive subject, with interpretation as locus or means of action depending on the verb. With transitives this is a body part belonging to the object, and construed as being involved in a patient role, as the locus at which the action is directed. (43a) contains examples of each type; in the first clause the root ngarrinj- 'hand' is incorporated, denoting the body part of the patient / object, while in the second clause the same root, again incorporated, is now construed as the body part of the intransitive subject. Incorporated body-parts with intransitive verbs may also have an instrumentlike interpretation with certain verbs, such as 'enter' in (43b), i.e. 'enter with its nose, enter as far as the nose is concerned, put nose in'. The possibility of incorporating body parts with an instrument-like function is never possible with transitive subjects, however, which must be encoded as instrumental-marked external nominals (43c; while incorporated nominals do not take suffixes marking their possessors, external nominals are always suffixed for possessor); when the semantics of the predicate makes it plausible to construe the body part with either subject or object, incorporated body parts must always be construed with the object (43d). 
(43a) Kodjdjan bûka-h-yûlûng-ngarrinj-dulubong wakbah-yih

DAL [name] 3A/3hObj-ASS-then-hand-spike:PP catfish-INSTR

ka-h-yûlûng-ngarrinj-kurlbabo-ng.

3S-ASS-then-hand-bleed-PP

'Then a catfish spiked Kodjdjan on the hand, and her hand bled.'

(and she bled, in her hand)

(43b) Yalang ka-h-ngu-n

ngarrarla kubud-kah,

DAL ant 3A/3loObj-ASS-eat-PR echidna anthill-LOC

ka-h-dje-birdika.

3S-ASS-nose-enterPR

'Echidnas eat ants, they put their noses (their noses enter) into anthills.'

(43c) Bûla-h-dalhmû

ngarrinj-bulng-yih.

DAL 3plA/3Obj-ASS-punchPR hand-3plPOSS-INSTR

'They (the footballers) punch the ball with their hands. ${ }^{, 46}$

(*bûla-h-ngarrinj-dalhmû)

(43d) Ka-h-ngarrinj-yidjnja-n.

DAL 3/1-ASS-hand-touch/hold-PR

'S/he is holding my hand.'

* 'S/he is touching me with her hand.'

Now body part incorporation can occur with reflexive/reciprocal verbs as well, and the body part must always be construed as a patient, never as an agent: (44a) means 'they looked into each other's eyes' not 'they looked at each other with their eyes' (e.g. looking at each other's faces, in a general way, without meeting their eyes), and

\footnotetext{
${ }^{46}$ In 'Aussie Rules' football, the code which this sentence was describing, players pass the ball to each other by punching it with their fists.
} 
(44b) means 'they shook hands, they grasped each other's hands', not 'they touched each other with their hands' ${ }^{47}$ This suggests that, even though the object is not present as an overt argument within the pronominal prefix, it must be present at some level of structure in order to licence the linking of the body part to the appropriate semantic role.

(44a) Barra-h-mim-na-rr-ûn.

DAL 3duS-ASS-eye-see/look-RR-PR

'They are looking into each other's eyes (they are lovers).'

(44b) Ke-h-langĥu-yidjnja-rr-inj.

\section{DAL 3du.disharmS-ASS-hand-hold-RR-PP}

'The two of them shook hands.'

Dalabon is not the only language in which this phenomenon occurs. In addition to the closely-related Bininj Gun-wok, into which these examples could be translated with no essential structural changes, a rather similar phenomenon is found in the Pama-Nyungan language Umpithamu (Verstraete MS), which by comparison with most Australian languages has some rather strict constraints on word order. There, the standard transitive construction for indicating action affecting the body part of the object is to place the body part in immediate preverbal position, in the (zero) accusative case, and in apposition to the actual object, also in the accusative (typically a pronominal object suffix, as in (45a). The immediate preverbal position it occupies is generally associated with object nouns. Reciprocal constructions employ a preverbal reflexive/reciprocal marker $p a \sim p a m a^{48}$, accompanied by a reduction in valency, since no overt object (pronominal or otherwise) may be present. Despite this, however, nouns denoting a body part of the patient (such as wukal 'cheek') may be placed in the regular object position, between the reflexive/reciprocal marker and

\footnotetext{
${ }^{47}$ Though of course, in practice, the commonest situation described by such predicates involves one where the body parts are involved in both capacities, e.g. in the second case where their hands are touching.

${ }^{48}$ Etymologically, this is a reduced form of pama 'person'; see Verstraete (MS) on the semantic and syntactic trajectory it has followed to end up as a reflexive/reciprocal marker in a number of Cape York languages.
} 
the verb. This is very similar to the Dalabon situation, except that the nominal is not incorporated in a strict sense since it is still a separate word.

(45a) apa'ala atha-n iluwa-athungku

UMP lower.leg(ACC) bite-PST 3sgNOM-3sgACC

'It bit me on the lower leg.'

(45b) pa wukal ngaympi-ngka ina

UMP RR cheek(ACC) hit-PRS 3plNOM

'They hit each other on the cheek.'

\subsubsection{Modal case on object body parts in Kayardild}

Another more complex example of an apparent mismatch between core argument structure and case marking in reciprocal constructions, as revealed by the treatment of body parts, comes from Kayardild (Evans 1995a). In regular transitive clauses in Kayardild, as in Warlpiri (§3.1), apposed body part NPs modifying the object are inflected with the same case as the object NP they modify. However, instead of a more familiar object-marking case like accusative or absolutive, they take a 'modal case' - a case varying with the tense, mood or aspect of the clause - which goes directly onto the stem of all words in the object NP, as well as onto some other nonsubject NPs, after other clause-level case marking (e.g. with instruments it follows the instrumental case).

(46) $\mathrm{NP}_{\text {<subj:nom> }} \mathrm{V} \quad \mathrm{NP}_{\text {<obj:modal case> }}\left(\mathrm{NP}_{\text {<obj:modal case> }}\right.$ [body.part ] $)$

In (47) the case of the object NP is the 'modal proprietive' (the case assigned to objects when the clause has 'potential' mood), and this is found on the apposed body part NP bardaka 'belly' also. ${ }^{49}$

\footnotetext{
${ }^{49}$ The case marking system of Kayardild is extremely complex and unusual, and it would take us too far afield to describe it in any detail here. The reader is referred to Evans (1995:Ch. 4) for detailed discussion.
} 
(47) Darri-n-kuru dangka-a

KAY tread.on-NMZR-PROP person-NOM

$\begin{array}{lll}\text { mirra-yala-thu } & \text { darri-ju maku-walath-u } & \text { bardaka-wu. } \\ \text { massage-POT } & \text { tread.on-POT woman-many-MPROP belly-MPROP }\end{array}$

'The person in charge of delivering the baby massages and treads on the women's bellies.'

In reciprocal constructions the object NP is suppressed and the clause appears intransitive. However, despite the fact that there is no possible object NP in the clause, apposed body parts on the (suppressed) object still appear in the relevant modal case (48):

(48) Dan-da maku-wala mirrayala-thu-th,

KAY this-NOM woman-many.NOM massage-REC-ACT

darri-nju-thu $\quad$ bardaka-wu.
tread.on-REC-POT belly-MPROP

'These women, they massage each other, they tread on each other's bellies (to induce labour).'

\subsection{Mismatch with overt transitivity markers}

Other examples of the ambiguous nature of reciprocal constructions with respect to transitivity parameters arise when the core arguments suggest a transitivity value for the clause which is contradicted by other aspects of morphosyntax.

Reciprocal/reflexive constructions in Yawuru, for example (Hosokawa 1991:173), take the suffix -ndyi- after the verb stem, and appear to be regularly intransitive in their argument structure and case marking: there is a single subject argument which appears in the nominative, and a single subject pronominal prefix. However, while 
the reflexive variant of the construction is consistent in also employing the intransitive verbal prefix -ma- (49a), reciprocal constructions normally $y^{50}$ employ the transitive prefix $-a$-instead (49b)..$^{51}$

(49a) Ingarr-ma-bura-ndyi-n kamba-rri.

YAW3augS-INTR-see-RR-IMP that-DU

'They (two) see themselves, respectively.'

(49b) Ingarr-a-bura-ndyi-n kamba-rri.

YAW 3augS-TR-see-RR-IMP that-DU

'They (two) see each other.'

\section{A further wrinkle: the situation with trivalent verbs}

Until now our discussion has focused primarily on the basic distinction between transitive (bivalent) and intransitive (monovalent) construction types. The situation becomes more complicated, however, when reciprocalised trivalent verbs are considered, since this allows us to check whether valency in reciprocals is being reduced by one, or to one. If the former, reciprocals of trivalent verbs should behave like two-place verbs (whether transitive or semi-transitive); if the latter, they should behave like one-place verbs. Unfortunately, very few grammatical descriptions are explicit about this distinction, or give sufficient examples that the question can be decided, or inconsistencies detected in a language's treatment. As a result, this section of our typological survey is shorter and less comprehensive than we would wish.

In a language with regular valence-reducing reciprocal constructions, such as the Papuan language Yimas, a reciprocalised transitive verb yields a canonical intransitive construction with the $\mathrm{S}$ (intransitive subject) rather than the A (transitive subject) form pronominal prefix $(50 a, b)$. Now if a reciprocal affix reduces the valence by one rather than to one, a reciprocalised ditransitive construction in such a language should yield a transitive clause with two arguments. This is in fact what we

\footnotetext{
${ }^{50}$ Hosokawa (1991:174) notes that verbs with first person inclusive subjects are an exception: the reciprocal forms of these verbs take intransitive prefixes, like reflexives.
} 
find in Yimas ${ }^{52}$, since the subject of a reciprocalized trivalent verb takes the $A$ (transitive subject) form of the pronominal prefix (50c). Note that pia in this example is a sort of lexical object prefix (Foley 1991:212-213), rather like an incorporated noun, representing the object 'talk, words' of the three-place verb 'tell'. The morphology of Yimas, then, makes it clear that reciprocals of three-place verbs have a valency of two - in other words, that their valency is reduced by one from the corresponding underived verb.

(50a) Na-kay-cay.

YIM 3sgObj-1plA-see

'We saw him.'

(50b) pa-tì-tpul

YIM 1plS-REC-hit

'We hit each other.'

(50c) Pia-kay-ci̇-i-kia-k.

YIM talk-1plA-REC-tell-NIGHT-IRR

'We tell each other.' (Foley 1991:285)

Before proceeding, we note a generalization that appears to be widespread if not universal in languages that form reciprocals by valence-changing verbal affix. In reciprocals from trivalent verbs, coreference is established between the subject and the indirect object - or, in languages where it may be more accurate to talk about two objects than about a direct and an indirect object, between the subject and that object which encodes human recipients or beneficiaries. ${ }^{53}$ In Bininj Gun-wok, for example

\footnotetext{
${ }^{52}$ For another, apparently comparable, example, this time from Ainu, see Tamura (2000). See also Bril (2002:154) for some examples of reciprocals of ditransitives in Nêlêmwa, a language that reduces valency in reciprocals. The presence of the ergative preposition $a$ in reciprocalized ditransitive derivations shows that they have a valence of two.

${ }^{53}$ Cf Aissen (1987:110) on Tzotzil ditransitives, which use the same structure (a special free pronoun form) for reflexives and reciprocals: 'In such clauses, most commonly associated with the semantics of reciprocals, the initial 1 and 3 are coreferential'; an example is:
} 
(Evans 2003a), which has a single reflexive/reciprocal suffix -rre-, when this is applied to the three-place verb wo- 'give', the subject must be interpreted as coreferential with the indirect object when a reciprocal reading is intended.

(51) Barri-wo-rre-ni.

\section{BGW 3plSUBJ-give-RR-PI}

'They used to give it ${ }^{54}$ to each other.'

*'They used to give each other to him.'

We now pass to three Australian languages where, in contrast to Yimas, the situation with reciprocals formed from ditransitives is less clear, with some grammatical features suggesting the resulting clause is transitive, and others suggesting it is intransitive. We have not been able to find any Australian examples comparable to Yimas, in which reciprocals of ditransitives exhibit so many relevant features of transitive clauses.

\subsection{Ndjébbana: intransitive prefix series but external object}

Ndjébbana is a non-Pama-Nyungan language belonging to the so-called Maningrida family (Green 2003), though it had earlier been classified as having isolate status. Verbs have two pronominal slots: one for subject and one for object or - in the case of ditransitives - for indirect object (McKay 2000:208). Except where the object is third person singular, the forms are distinct: cf barra- ' 3 augmented ${ }^{55}$ subject' and banbirri- 'third person augmented subject acting on third person augmented object'.

Reflexive and reciprocal clauses are derived by suffixing $-y i$ - to the verb stem and reducing the valence. McKay's (2000) grammar of Ndjébbana states clearly that reflexive/reciprocal clauses are 'like any other intransitive clause' (p. 290) and that

\footnotetext{
(i) 7i-y-ak'-be s-ba-ik k'ok'

completive-3A-give-APPLIC 3A-self-pl fire

'They fired on each other.' (Lit. 'They gave fire to each other.')

${ }^{54}$ Although no overt object coding appears in this example, the presence of a second argument position construed as 'it' is shown by the possibility of noun incorporation (Evans 2003).

55 'Augmented' is similar to plural, but counts from a minimum that varies with the composition of the group by person: from one for most, but from two for first person inclusive, whose logical minimum is 'you' plus 'me'.
} 
'[a] verb derived using the $-y i$ - prefix [sic] is intransitive and therefore takes an intransitive pronominal prefix marking the $\mathrm{S}$ or the sentence. It may not take a transitive prefix form, unlike the transitive or ditransitive verb it may be derived from' (p. 263; italics ours). The difference between transitive (in underived) and intransitive (in derived) prefix sets with a base transitive verb is clearly shown, with a reflexive example, in (52):

(52a) Banda-mérba-ra.

NDJ 3minA/3augObj-hide-CTP

'He is hiding them.'

(52b) Barra-mérba-ya.

NDJ 3augS-hid-REFL:CTP

'They are hiding (themselves).'

(52c) *banda-mérba-ya

NDJ $3 \operatorname{minA} / 3$ augO $^{56}$-hide-REFL:CTP

Despite the use of intransitive pronominal prefixes, there is other evidence that the result of adding $-y i$ - to a three-place verb is a two-place rather than an intransitive verb. McKay (2000:264) cites a reciprocal use with the 'base verb ... djébba 'deprive someone of something, take something away from someone, ${ }^{57}$, a ditransitive verb with which the transitive prefix would mark the A and the IO. In the derived reciprocal form the $\mathrm{S}$ prefix marks the three players as functioning both as $\mathrm{A}$ and as IO towards one another in the struggle for the ball, giving the following example:

barra-ddjébba-ya budborl.

NDJ 3augS-deprive.of-RR:CTP football

'...they are trying to get the ball [=are trying to deprive each other of the ball]'

\footnotetext{
${ }^{56}$ Presumably the form with the 3 augA/3augO prefix, namely banbirri-mérbaya, is also unacceptable.
} 
Although McKay does not discuss the status of budborl 'football', ${ }^{58}$ it appears to function exactly as it would if it were the direct object of a transitive verb: as a free nominal, unmarked for case, directly next to the verb. It therefore appears plausible that the reciprocal verb $(d)$ djébbaya behaves like a one-place verb in terms of its selection of pronominal prefixes, but like a two-place verb in terms of its possession of a second argument able to be expressed by a directly adjacent unmarked NP.

\subsection{Dalabon: 'intransitive’ prefix series but incorporated object}

A more complex example is Dalabon, where we are able to formulate tighter tests for object status than is possible in Ndjébbana. There are a number of lines of evidence showing that both non-subject elements really are arguments in languages like Dalabon and Bininj Gun-wok - see Evans (1995b, 1997) for the full arguments and relevant evidence regarding Bininj Gun-wok. The main evidence is that (a) the scope of some bound quantifiers, which are restricted to objects and intransitive subjects, can include the theme object (b) for selected person combinations of theme and recipient (like 'they showed me to him'), the theme object can actually bump out the recipient object from the pronominal object slot (c) both object positions can feed the reflexive/reciprocal construction (marked with the same verbal suffix form): the theme object with a reflexive interpretation ('they showed themselves to us') and the recipient object with a reciprocal interpretation ('they showed the meat to each other'). It is thus clear that, in the base construction, we really are dealing with two objects in the broad sense - though none of the standard terminological contrasts (like primary vs secondary object, direct vs indirect object) apply felicitously to the Bininj Gun-wok system or to Dalabon (see Evans 2003a:391-2).

Apart from the special case of incorporated body parts ( $\$ 4.3 .1$ above), nominals in Dalabon - like in the closely related Bininj Gun-wok (Evans 1997, 2003a), and like in many other languages around the world - incorporate on an absolutive basis.

Transitive verbs can incorporate their objects (54a) and intransitive verbs incorporate their subjects (54b). In both of these cases this can result in double exponence, since

\footnotetext{
${ }^{58}$ This is McKay's example, and he glosses the barra- prefix as intransitive. In email correspondence with NE (6/4/04) he confirms the direct object status of budborl in this example and notes, that, given the existence of homophonous transitive forms with third person minimal objects this data needs further checking to confirm whether the pronominal prefix is transitive or intransitive.
} 
the absolutive is representable by both incorporated noun and pronominal affix (though in effect visible double exponence is reduced by the fact that only around forty nominals can incorporate, mostly referring to inanimates). With ditransitives, the recipient gets represented by the object pronominal slot, while the theme incorporates (54c); the same pattern is found with derived trivalent verbs formed by adding the benefactive applicative marn $\hat{u}$ - to a transitive base, as in (54d), where the benefactive applicative is used to introduce a possessor in the object pronominal slot. ${ }^{59}$

(54a) Boyenj-boyenj ka-h-lam-yu.

DAL big-big 3sgS-ASS-mineral.nodule-liePR

'There are lots of mineral nodules there.'

[Lit. 'lots of mineral nodules lie there']

(54b) Bula-h-bad-yunginj.

DAL 3plA/3sgObj-ASS-rock-put.downPP

'They put the rocks (rock?) down (there).'

(54c) Ka-h-kanj-drahm-inj.

DAL 3sgA/1sgObj -ASS-meat -not.give-PP

'He wouldn't give me the meat, he refused me the meat.'

(54d) Bûka-h-marnû-yaw-nanhna-n.

DAL 3sgA /3sg.hiObj-ASS-BEN-child-look.after-PR

'She looks after his child.'

Now in reciprocal constructions formed from three-place verbs, the 'monovalent' or intransitive prefix set is used, whether with base trivalent verbs like drahmû 'withhold, not give' (55a) or with base bivalent verbs to which a third argument has been added by the benefactive applicative, like marnû-nahnan 'look after X for Y; look after Y's X' (55b). But though the verb takes a monovalent prefix, as an intransitive verb would, the incorporated argument is not coferential with the (sole)

\footnotetext{
${ }^{59}$ The situation with the other applicatives - the comitative, instrumental, and (incipient) locative - is more complicated, and will not be discussed here.
} 
pronominal prefix, as would be the case in a true intransitive; rather it is the theme, as one would expect from the object of a transitive. As an alternative to incorporation, the second argument may be represented by an external NP next to the verb (55c); this is also a possibility with normal transitive verbs.

(55a) Barra-h-kanj-drahm-irr-inj,

kardû barra-h-ngurrngdu-rr-un.

DAL 3duS-ASS-meat-not.give-RR-PP maybe 3duS-ASS-hate-RR-PR

'They two wouldn't give each other meat, maybe they hate each other.'

(55b) Barra-h-marnû-yaw-nanhna-rr-ûn.

DAL 3duS -ASS-BEN-child-look.after-RR-PR

'They look after each other's children.'

(55c) Barra-h-drahm-irr-inj,

kanj-no.

DAL 3duS-ASS-not.give-RR-PP meat-3sgPOSSD

'They two wouldn't give each other the meat.'

A further piece of evidence that reciprocalized ditransitive verbs still have two arguments comes from the fact that the ergative use of the instrumental, optionally found on the subjects of transitive clauses as in (56), sometimes appears with reciprocals of ditransitive verbs; this contrasts with reciprocals of transitives, with which it is so far unattested.

(56) Wurdurd-yih yabbunh barra-h-ngabbu-rr-inj,

DAL child-INSTR two 3duS-ASS-give-RR-PP

barra-h-yurrmirr-inj.

3duS-ASS-swap-PP

'The two kids give each other (food), they swap (food).'

The evidence from reciprocals formed from three-place verbs in Dalabon, is clearly divided on the question of valence: the pronominal prefixes are those found with 
intransitive, monovalent verbs, while the behaviour of incorporated nominals, and the availability of instrumental/ergative marking on subjects, are those found with transitive, divalent clauses.

\subsection{Nominative: accusative ( $S: O)$ case frames in Wambaya reciprocals of ditransitives}

As we saw in $§ 3.2 .1$, Wambaya exhibits another type of mismatch in reciprocalised ditransitive constructions. In this case, the subject appears in nominative, rather than ergative case, despite the presence of an overt object NP, as in (57) (repeated from (38) above). This is the only time in Wambaya that an accusative object co-occurs with a subject in the nominative rather than the ergative case: based on the case assigned to the object, the clause looks transitive, while based on the case assigned to the subject, it looks intransitive.

Ngarringga wurlu-ngg-a alaji gambada wardangarri.

WMB take.from 3duA-RR-NF child(ACC)sun(NOM) moon(NOM)

'The sun and the moon took each other's child.' [lit. The sun and the moon took a/the child from each other.] (Nordlinger 1998:239)

\subsection{Objects and trivalent reciprocals: summary}

What is common to all three of the Australian languages for which we have (at least some) data on reciprocals in ditransitives is that the choice of either an intransitive pronominal-prefix form (Dalabon, Ndjébbana ${ }^{60}$ ), or nominative/absolutive rather than ergative case for the subject (Wambaya) is made in spite of the presence of an object. Coreference is established between the subject and the indirect object, and there is no overt nominal exponent of the indirect object actant. However, the third, theme actant remains in the clause, and can be present as an external NP (Ndjébbana, Wambaya, Yanyuwa) or an incorporated object argument (Dalabon); either the case marking it receives (absolutive or accusative, according to the language) or its incorporation properties (Dalabon) mark it as a normal direct object. The fact that the subject argument is encoded by an intransitive prefix (Dalabon, Ndjébbana, Yanyuwa) or in

\footnotetext{
${ }^{60}$ Yanyuwa is a further example of a language that uses the intransitive prefix with reciprocalized ditransitive verbs, even in the presence of an object - see Kirton \& Charlie (1996:124-5).
} 
nominative or absolutive case (Wambaya, Yanyuwa) does not signal, as it would in a normal clause, the absence of an object. In all these cases, then, the grammatical treatment of reciprocals of ditransitives suggests that we have a different sort of mixed transitivity: the form of the pronominal prefix, or the case assigned to the subject, suggests that the valence has been reduced to one, while the presence of a remaining direct object shows that it has in fact simply been reduced by one. ${ }^{61}$

One possible explanation for this conundrum is in terms of the semantic representation for prototypical reciprocal scenarios that we proposed, in the introduction, projects predicates of different valencies onto the clause. The element 'do jointly/together' is still a monovalent predicate whether it is being used with reciprocals of two- or three-place verbs, and can therefore be used to motivate the presence of an intransitive pronominal prefix or of a case on the subject that is characteristic of intransitive clauses; the object is a direct projection from the theme position of the unidirectional predicates.

Though the evidence we have seen in this section shows that theme objects from the unidirectional predicates can remain in reciprocalized trivalent clauses, our discussion in $\S 4$ of residual evidence of an object position in reciprocals of bivalent verbs raises an intriguing further question. Could we could find evidence of residual indirect objects in reciprocals of three-place verbs - something that would be predicted on the predicate-conflation model? Could we apply, to ditransitives, the sorts of tests for the implicit presence of the coreferential indirect object argument that we applied in $\S 3$ and $\S 4$ to transitives - what happens with secondary predications, complement clauses and so forth? These would be fascinating questions to pursue, but unfortunately we have yet to find a skerrick of relevant data in the descriptions we have, so further research on this will have to wait until more detailed grammatical data on reciprocals of trivalent verbs becomes available.

\footnotetext{
${ }^{61}$ The only other area of the grammars of Australian languages in which S:O (nominative:accusative), as opposed to A:O (ergative:accusative) case frames sometimes occurs is in 'cognate object' constructions like 'speak (a language)', 'play (a game)' etc: Austin (1982) cites examples from Diyari, Djaru, Bayungu, Guugu Yimidhirr and Yidiny with a handful of verbs which take a subject in the nominative (S) case and optionally an accusative object. Interestingly cognate object constructions in another language, Banjalang, have a sole argument in the ergative, another aberrant core case pattern we have mentioned in this paper (see $\$ 4.1 .1$ ).
} 


\section{Further issues}

\subsection{Overview of ways in which reciprocals can exhibit valency mismatches}

Our first goal in this paper was to show how many different guises valency mismatches can take in reciprocals, beyond such phenomena as auxiliary selection that are already widely known. The Australian languages we have examined show many novel manifestations of valency mismatches, each posing a problem for any treatment that would see reciprocals having a fixed arity at all levels of representation.

With regard to reciprocals formed from base divalent clauses, these can take the form of anomalous case choice, most importantly the use of ergative case marking on single core arguments (Badjala, Bunuba, Gooniyandi, Kuuk Thaayorre) but also, in some languages, the use of ergative/instrumental case on instruments where this use is normally confined to transitive clauses (Alyawarr, Yalarnnga). A variety of NPs linked through case choice to the subject or object NP may also behave as if the clause is transitive, despite the lack of an overt object, and take case-marking (ergative or accusative) normally restricted to transitive constructions: this is found with both secondary predicates and body part predicates in Alyawarr.

The apparent suppression of object arguments in reciprocals may fail to impact on the treatment of body-parts which, in normal transitive clauses, would be syntactically apposed to the object. According to the language, this may result in object-like case assignment to the body part (Kayardild) or incorporation (Dalabon) or noun placement (Umpithamu) in ways characteristic of objects. Overt markers of transitivity on the verb may be found in reciprocals despite the presence of just one pronominal argument prefix, as in Yawuru.

Trivalent clauses present a different set of phenomena in a number of languages. Though here the indirect object is suppressed under coreferentiality with the subject, with concomitant substitution of the ergative case by the nominative on the subject, or of a divalent pronominal prefix set with a monovalent one, the direct object remains overt in the reciprocal clause, as an external or incorporated nominal, typically creating an $\mathrm{S}: \mathrm{O}$ as opposed to an A:O case frame.

\subsection{Does clausal transitivity correlate with encoding strategy?}

Early in this paper we cited Faltz' (1985:14-15) influential suggestion that method of encoding had an impact on transitivity, which suggested that NP coding would 
correlate with transitive features, and verb coding would correlate with intransitive features. We will refer to this as the 'coding strategy hypothesis'. For the Australian languages that we have discussed in this paper, we can translate this into two broad strategies for encoding reciprocity - pronominal coding (by means of a bound or free reciprocal pronoun, or clitic), and verb-coding (typically by means of a verbal affix that does not itself directly represent an argument). ${ }^{62}$ Note that this does not exhaust the possible means of encoding reciprocity - some languages use particles, or adverbials like 'mutually' or 'in return', or juxtapose two clauses - but these are rarer and lie outside the scope of this paper. See also König \& Kokutani (2006) and Evans (forthcoming) for more extended typologies.

The coding strategy hypothesis has underlain a number of treatments of the phenomenon, and is certainly a broad tendency, but the data considered in this paper suggest the situation is much less simple.

One way it needs to be modified, of course, is to recognize that there is no single value for 'valency' or 'transitivity' in reciprocal constructions that predicts the behaviour of all relevant grammatical phenomena; throughout the paper we have seen that within particular languages, different tests jump different ways. Table 2 presents a summary of the various indicators ${ }^{63}$ found in the reciprocal constructions of nineteen Australian languages.

[Table 2 about here]

It might still be possible to adapt the coding-strategy hypothesis to this more complex data: for example, it may be possible to claim that languages with pronominal reciprocal strategies exhibit purely transitive behaviour on all fronts (English or Warlpiri style), while mixed transitivity behaviour is only found on

\footnotetext{
${ }^{62}$ This contrast is similar to Dixon's (2002:320) distinction between using 'a special reflexive/reciprocal pronominal element' and a 'verbal derivational affix' strategy, respectively. ${ }^{63}$ It should be noted that many of these indicators are language-specific; for instance, marking an instrument with ergative case is indicative of a transitive clause in, e.g., Alyawarr, but not in, e.g., YirYoront. The case-marking of instruments is therefore listed as an indicator of transitivity only for languages such as the former.
} 
languages with verbal-coding strategies.$^{64}$ It is this revised version of the codingstrategy hypothesis that we now examine.

An overall impression of the data considered in this paper can be gained by looking at the italicized entries in Table 2, which indicate a mismatch between the transitivity-behaviour of a particular construction and that which we would expect from the coding strategy. This occurs where a construction exhibits intransitive characteristics, but is associated with a pronominal encoding strategy, or conversely if the construction exhibits transitive characteristics, but is associated with a verbcoding strategy. Let us call such cases 'non-congruent constructions'.

On the original form of the coding-strategy hypothesis, we should expect no italicized entries; on the revised form, we should only expect italicized entries for languages with a verb-coding strategy. In fact, however, non-congruent constructions are found in both verb-coding and pronominal-coding languages. Importantly, though, we have not located any Australian language with verb coding but both argument positions representable by overt NP material (pronominal or otherwise): this would be a language where you say something like 'they fought-each-other them'. Because the number of overt arguments is usually the first piece of information that a grammar gives in its section on reciprocal marking, and because of the large number of languages that employ this strategy in Australia, this is a significant finding.

However, consideration of other non-Australian languages suggests one can find examples, albeit rare. The New Caledonian language Nêlêmwa (Bril 2002, 2005) marks subjects by preverbal pronominals and (optional) postverbal NPs preceded (if the clause is transitive) by the ergative preposition $a$, and objects by pronominal suffixes on the verb (58a). There are two basic reciprocal constructions: an

\footnotetext{
${ }^{64}$ A diachronic version of this hypothesis would suggest that if a reciprocal marker gets reanalysed from being a pronoun, to being a valence-changer on the verb, there would be an accompanying change from leaving the valence intact, to reducing valence. This seems to be implicit in Dixon's (2002:324) remarks about the Warluwarric family, in which he discusses the development of reflexive/reciprocal pronouns from an original free status, attested in Warluwarra, to bound prefixes, and the apparently correlated fact that reciprocals are transitive in Warluwarra but intransitive in Yanyuwa. Though this scenario remains interesting, it must be pointed out that other possible explanations exist, such as areal convergence between Yanyuwa and its southerly neighbours Karrwa and Wanyi, in which reciprocals are also intransitive even though the reflexive/reciprocal pronouns are clitics rather than verbal affixes; in any case, on our typology, the Yanyuwa prefixes are a pronominal coding strategy even though they are part of the verbal word.
} 
intransitive one (58b) where the verbal confix pe-...-i combines with a monovalent construction $^{65}$ (though it may be double represented, once by a preposed subject pronoun and once by a postverbal full NP), and a transitive one (58c) where the prefix $p e$ - (i.e. the first part of the confix pe-...-i) combines with a clause type in which both subject and object are represented.

(55a) Hli yage-i-hli a hliili meewu.

NEL 3duSub help-TR-3du.O ERG these2anaph brother

'These two brothers help them.'

(55b) $\mathrm{Hli} \quad$ pe-thiwalaxa-i âlô mahliili.

NEL 3duSub REC-tickle-REC child these2DEIC

'These two children tickle each other.'

(55c) $H l i \quad$ pe-tuâ-i-hli.

NEL 3DUSub REC-deceive-TR-3duObj

'They deceived each other.'

Table 2 presents several examples of incongruence in languages with pronominal encoding. There are a number of languages which employ just a single reflexive/reciprocal form for transitive clauses, combining it with an underived transitive verb: this may be a clitic (Karrwa, Wanyi, Yaraldi) or a pronominal prefix to the verb (Yanyuwa). There are also languages which employ a special reflexive/reciprocal pronominal form in the object slot of the auxiliary, but which use a case frame appropriate to intransitives (Wambaya), and where the syntactic behaviour of subordinate clauses suggests that there is just one actant in the main clause (Wambaya again).

Overall, then, even in its revised form, the coding-strategy hypothesis cannot be maintained, except as a tendency. This is an area, however, which warrants revisiting

\footnotetext{
${ }^{65}$ Note, though, that Bril (2002:153) points out that in this construction 'Les verbes ont généralement une flexion transitive (ou une forme apparantée), mais la construction est monovalente, comme la forme réfléchie. C'est encore la preuve que flexion transitive et valence ne sont pas automatiquement liées.'
} 
once we have comparable data across a much broader sample of languages than data is currently available for.

\subsection{Motivating valency mismatches}

As discussed in $§ 1-2$, reciprocal constructions lend themselves naturally to such mismatch effects precisely because they constitute an unusual combination of multiple semantic participants on the one hand, and linking to multiple argument roles on the other. Additionally, at least in the prototypical case, their semantics conflates both multivalent unidirectional predicates and a monovalent predicate of the type 'do together/jointly'. Though some languages (like the Papuan language Amele) distribute these various predicates over several chained clauses, most languages have grammaticalized their encoding to express reciprocity in the confines of a single clause, but this then creates a mapping problem: which predicate - and in particular which valency - is to determine the morphosyntactic features of the reciprocal clause? The split valence effects we have been examining represent a number of compromise solutions by which different aspects of the clause reflect different predicates from the semantic representation.

We need here to mention one weakness in this account: the fact that at least some of the types of valency mismatches we have discussed in this paper are also found with reflexive constructions, for which the crucial one-place predicate 'do together/jointly' is not part of the semantic representation, and can thus not be used to motivate the structure. There are a number of rejoinders to this position. Firstly, in languages with a dedicated reciprocal construction - such as Kayardild - the behaviour of reciprocals needs to be accounted for directly anyway, without reference to reflexives. Secondly, at least some of the effects we have been discussing - such as the optional use of the ergative case in Bunuba, Kuuk Thaayorre and Badjala (§4.1.1) - the mismatch effect is only found with reciprocals, not with reflexives. Thirdly, since there are many cases in Australia (e.g. Bininj Gun-wok, Dalabon, Nyulnyulan) where reflexive/reciprocal affixes on verbs have developed by extending the function of an original reciprocal marker to take in reflexives, it is not impossible that some mixed-valency traits in those languages are due to the reciprocal origins of the construction. These are of course only partial counterarguments to this objection, and 
an important question for future research is to determine how far the subtle effects we have examined in this paper are also true of reflexive constructions.

In the case of some phenomena, reciprocals can be seen as creating the highly specific conditions necessary to tease apart the different aspects of the linguistic system that grammatical phenomena are sensitive to. In a prototypical (nonreciprocal) transitive clause many, if not all, of the various grammatical phenomena we have addressed above fall together: subjects may be marked with ergative case, instruments with the instrumental case, the clause may have two overt arguments, verbs may have divalent pronominal prefixes, and so forth. Basing one's analysis on such prototypical transitive clauses, it is natural to attribute all of these grammatical phenomena to the syntactic transitivity of the clause as a whole.

Reciprocal constructions with mixed effects, however, provide insight into more complex and intricate conditioning factors for these phenomena. For example, the possibility of instrumental case in otherwise intransitive reciprocal constructions in languages like Alyawarr (that otherwise restrict its occurrence to transitive clauses) suggests that instrumental case in these languages is not sensitive to the transitivity of the clause per se, but to the presence of both agent and patient roles in the semantic structure. Reciprocal constructions provide one of the few opportunities to disassociate such bivalency at a semantic level from syntactic transitivity, thus explaining why it is only in these constructions that such apparent 'mismatches' are revealed. ${ }^{66}$

Similarly, the appearance of the ergative case on the single argument of reciprocal constructions in languages like Badjala and Kuuk Thaayorre suggests that the function of the ergative case in these languages is not to mark a clause as transitive at the syntactic level, but rather to indicate the presence of an agent-patient array in the thematic structure.

Furthermore, the presence of 'object' case agreement on body parts in otherwise intransitive reciprocal constructions in Kayardild suggests that the phenomenon of case agreement is not, in fact, solely a syntactic phenomenon as generally assumed,

\footnotetext{
${ }^{66}$ Another opportunity arises in anti-passive (and passive) constructions, in which the clause becomes syntactically intransitive, but retains the same array of thematic roles in the semantic argument structure. Interestingly, Australian languages with antipassive constructions frequently allow the use of the instrumental case in these constructions types also; see Dixon (2002:136) and §4.2.
} 
but rather a more complex interaction of syntactic and semantic argument structure. Case morphology in these examples is not simply 'agreeing' with a syntactic argument, but rather signalling the presence of a particular thematic role in the semantics. The mixed behaviour of reciprocal constructions then, may not in fact signal 'mixed' transitivity at the syntactic level at all.

As we have shown here, reciprocal clauses provide a particularly complex and sensitive laboratory for teasing apart the relative contributions of semantics and syntax to argument structure, and the various ways in which languages have fashioned constructions which accommodate the conflicting motivations posed by different predicate elements in the complex, overlaid semantic representations that are the hallmark of reciprocal semantics. Many complexities emerge once sufficiently rich data on reciprocals becomes available. We hope that investigators will see the value in pushing for more detailed field data on reciprocals than has been the norm to date, and have no doubt that as this emerges we will be provided with greater insight into the intriguing nature of argument structure in this intricate clause type.

\section{References}

Aissen, Judith. 1987. Tzotzil Clause Structure. Dordrecht: D. Reidel Publishing Co.

Alpher, Barry. 1973. Son of ergative: the Yir-Yoront language of northeast Australia. Unpublished Ph.D. Dissertation, Cornell University.

Alpher, Barry, Evans, Nicholas \& Harvey, Mark. 2003. Proto-Gunwinyguan verb suffixes. In N. Evans, ed., The non-Pama-Nyungan languages of northern Australia: comparative studies of the continent's most linguistically complex region. Canberra: Pacific Linguistics. Pp. 305-352.

Alsina, Alex. 1996. The role of argument structure in grammar. Stanford: CSLI Publications.

Arka, I Wayan. In prep. On the Balinese ma-: Iconicity, markedness and reflexivity. Atsarkina, T.A. 1963. Vosvratnyj glagol'nyj komponent si v sovremennom cheshskom jazyke. In A. G. Shirokova (ed.) Issledovanija po cheshskom jazyku. Moscow: Izdatel'stvo AN SSSR. Pp. 86-104.

Austin, Peter. 1982. Transitivity and cognate objects in Australian languages. In Paul J. Hopper \& Sandra A. Thompson (eds.) Syntax and semantics, Vol. 15. Studies in Transitivity. New York: Academic Press. Pp. 37-48. 
Bell, Jeanie. 2003. A sketch grammar of the Badjala language of Gari (Fraser Island). Unpublished M.A. Thesis, Department of Linguistics \& Applied Linguistics University of Melbourne.

Besnier, Niko. 2000. Tuvaluan: a Polynesian language of the Central Pacific. London: Routledge.

Blake, Barry J. 1977. Case marking in Australian languages. Canberra: AIAS. Blake, Barry J. 1979. A Kalkatungu grammar. Canberra: Pacific Linguistics. Blake, Barry J. 1987. Australian Aboriginal Grammar. London: Croon Helm. Breen, Gavan. 1976 a. Ergative, locative and instrumental inflections in Wagaya. In R.M.W. Dixon (ed.), Grammatical categories in Australian languages. Canberra: AIAS. Pp. 336-339.

Breen, Gavan. 1976b. Ergative, locative and instrumental inflections in Warluwara and Bularnu. In R.M.W. Dixon (ed.), Grammatical categories in Australian languages. Canberra: AIAS. Pp. 331-335.

Breen, Gavan. Forthcoming. Warluwarra grammar.

Bril, Isabelle. 2002. Le nêlêmwa (Nouvelle-Calédonie). Analyse syntaxique et sémantique. Paris: Peeters.

Bril, Isabelle. 2003. Middle voice and "reciprocal" prefixes in Austronesian and New Caledonian languages. Linguistic Typology [give full ref]

Bril, Isabelle. (To appear). Polysemy of the reciprocal marker in Nêlêmwa. To appear in V. Nedjalkov \& Z. Guentcheva (eds.), Typology of Reciprocal Constructions. München: Lincom Europa.

Burzio, Luigi. 1986. Italian syntax: A government-binding approach. Dordrecht: Reidel. [Revision of 1981 MIT dissertation]

Cerin, Mark. 1994. The pronominal system of Yaraldi. Honours Minor Thesis, Department of Linguistics, University of Melbourne.

Clark, Herbert H. \& Thomas B. Carlson. 1982. Speech acts and hearers' belief. In N.V. Smith (ed.) Mutual Knowledge. London: Academic Press. Pp. 1-136.

Craig, Colette G. 1976. Disambiguation and hierarchies in Jacaltec. In M. McClaran (ed.) Mayan Linguistics. American Indian Studies Center, UCLA. Pp. 141-160. Crowley, Terry. 1978. The middle Clarence dialects of Bandjalang. Canberra: AIAS. 
Dalrymple, Mary, Kanazawa, Makoto, Kim, Yookyung, Mchombo, Sam and Peters, Stanley 1998, Reciprocal Expressions and the Concept of Reciprocity. Linguistics \& Philosophy 21.2: 159-210.

Dench, Alan. 1997. Reflexive constructions in the Pilbara languages of Western Australia. Paper presented to Department of Linguistics, Freie Universität, Berlin. Dixon, R.M.W. 1972. The Dyirbal language of North Queensland. Cambridge: CUP. Dixon, R. M. W. 1976. Yidinj. In R. M. W. Dixon (ed.) Grammatical Categories in Australian languages. Canberra: AIAS. Pp. 315-320.

Dixon, R.M.W. 1980. The languages of Australia. Cambridge: CUP.

Dixon, R.M.W. 2002. Australian languages. Cambridge: CUP.

Donaldson, Tamsin. 1980. Ngiyambaa. The language of the Wangaaybuwan. Cambridge: CUP.

Eades, Diana. 1979. Gumbaynggir. In R.M.W. Dixon \& Barry J. Blake (eds.), Handbook of Australian Languages, Vol. 1. Pp. 244-361.

Edmonson, J.A. 1978. Ergative languages, accessibility hierarchies governing reflexives and questions of formal analysis. In W. Abraham (ed.), Valence, semantic case, and grammatical relations. Amsterdam: John Benjamins. Pp. 633660.

Evans, Nicholas. 1995a. A grammar of Kayardild. Berlin: Mouton de Gruyter.

Evans, Nicholas. 1995b. A-quantifiers and scope in Mayali. In Emmon Bach, Eloise Jelinek, Angelika Kratzer and Barbara Hall Partee, eds, Quantification in natural language. Dordrecht: Kluwer. Pp 207-270.

Evans, Nicholas. 1997. Role or cast? Noun incorporation and complex predicates in Mayali. In Alex Alsina, Joan Bresnan \& Peter Sells, eds. Complex Predicates. Stanford: CSLI. Pp. 397-430.

Evans, Nicholas. 2003a. A pan-dialectal grammar of Bininj Gun-wok (Arnhem Land): Mayali, Kunwinjku and Kune. (2 vols.) Canberra: Pacific Linguistics.

Evans, Nicholas. 2003b. Comparative non-Pama-Nyungan and Australian historical linguistics. In N. Evans, ed., The non-Pama-Nyungan languages of northern Australia: comparative studies of the continent's most linguistically complex region. Canberra: Pacific Linguistics. Pp. 3-25.

Evans, Nicholas and Francesca Merlan. 2003. Dalabon conjugations. In N. Evans, ed., The non-Pama-Nyungan languages of northern Australia: comparative studies of 
the continent's most linguistically complex region. Canberra: Pacific Linguistics. Pp. 269-283.

Evans, Nicholas, Merlan, Francesca, and Maggie Tukumba. 2004. A first dictionary of Dalabon.

Evans, Nicholas. 2006. Complex events, propositional overlay and the special status of reciprocal clauses. In Sally Rice \& John Newman (eds.), Empirical and experimental methods in cognitivelfunctional research. Stanford: CSLI.

Evans, Nicholas. Forthcoming. Reciprocal constructions: towards a structural typology. In Ekkehard König \& Volker Gast (eds.) Reciprocals: cross-linguistic and theoretical explorations. Berlin: Mouton de Gruyter.

Evans, Nicholas, Ruth Singer and Bruce Birch. Forthcoming. The Iwaidja/Mawng reciprocal: a challenge to the typology of reciprocal constructions.

Everaert, Martin. 1999. Types of anaphoric expressions: reflexives and reciprocals. In Frajzyngier \& Curl (eds.), Reciprocals: forms and functions. Amsterdam: John Benjamins. Pp. 63-84.

Faltz, Leonard M. 1985. Reflexivization. A Study in Universal Syntax. New York: Garland.

Fiedler, W. 1972. Reflexiv und Medium im Bulgarischen. Zeitschrift für Slawistik 17.3:380-393.

Foley, William A. 1991. The Yimas language of New Guinea. Stanford: Stanford University Press.

Furby, E.S. and C.E. 1977. A preliminary analysis of Garawa phrases and clauses. Canberra: Pacific Linguistics.

Gaby, Alice. 2001. A typology of the reflexoid in Australian languages. Unpublished B.A. (Hons) thesis, Department of Linguistics \& Applied Linguistics, University of Melbourne.

Gaby, Alice. 2006. A Grammar of Kuuk Thaayorre. Ph. D. thesis, Department of Linguistics and Applied Linguistics, University of Melbourne.

Gaby, Alice. Forthcoming. "Pragmatically case-marked: non-syntactic functions of the Thaayorre ergative suffix". In Ilana Mushin and Brett Baker (eds.) Discourse and grammar in Australian languages. Amsterdam: John Benjamins. Geniusiene, Emma. 1987. The typology of reflexives. Berlin: Mouton de Gruyter. 
Georgiev, I.S. 1972. Struktura i semanticheskie osobennosti odnoj bezlichnoj konstrukcii v russkom i bolgarskom jazykax. Filolologicheskie nauki 3:98-105.

Goddard, Cliff. 1982. Case systems and case marking in Australian languages: a new interpretation. Australian Journal of Linguistics 2:167-196.

Goddard, Cliff. 1983. A semantically-oriented grammar of Yankunytjatjara. Unpublished Ph.D. Thesis, Australian National University.

Green, Ian. 1989. Marrithiyel: a language of the Daly River region of Australia's Northern Territory. Unpublished Ph.D. Dissertation, Australian National University.

Green, Ian. 1995. The death of 'prefixing': contact-induced typological change in Northern Australia. Berkeley Linguistics Society 21:414-425.

Green, Ian and Rachel Nordlinger. 2004. Revisiting Proto-Mirndi. In Claire Bowern and Harold Koch (eds) Australian languages: classification and the comparative method, No. 249 Current Issues in Linguistic Theory. Amsterdam: John Benjamins. 291-311.

Green, Jennifer. 1992. Alyawarr to English dictionary. Alice Springs: Institute for Aboriginal Development.

Green, Rebecca. 2003. Proto Maningrida within Proto Arnhem: evidence from verbal inflectional suffixes. In N. Evans, ed., The non-Pama-Nyungan languages of northern Australia: comparative studies of the continent's most linguistically complex region. Canberra: Pacific Linguistics. Pp. 369-421.

Hale, Kenneth. 1968. Preliminary remarks on Walbiri grammar. Unpublished ms, MIT, Cambridge, Massachusetts.

Hale, Kenneth. 1981. Preliminary remarks on the grammar of part-whole relations in Warlpiri. In Jim Hollyman and Andrew Pawley (eds.) Studies in Pacific linguistics in honour of Bruce Biggs. Auckland: New Zealand Linguistic Society. Pp. 333-344.

Hale, Kenneth. 1982. Some essential features of Warlpiri verbal clauses. In Steven Swartz (ed.) Papers in Warlpiri grammar: in memory of Lothar Jagst. Darwin: SIL-AAB. Pp. 217-315.

Hale, Kenneth, Mary Laughren \& Jane Simpson. 1995. Warlpiri. In Joachim Jacobs, Arnim von Stechow, Wolfgang Sternefeld and Theo Vennemann (eds.) Syntax. Ein internationales Handbuch zeitgenössischer Forschung. An International 
Handbook of Contemporary Research. Berlin: Water de Gruyter. Pp. 14301451.

Harvey, Mark. 2002. A grammar of Gaagudju. Berlin: Mouton de Gruyter.

Harvey, Mark, Ian Green and Rachel Nordlinger. 2006. From prefixes to suffixes: typological change in northern Australia. Diachronica 23(2): 289-311.

Haviland, John. 1979. Guugu Yimidhirr. In R.M.W. Dixon and Barry J. Blake (eds) Handbook of Australian Languages. Canberra: ANU Press. Pp. 26-180.

Heim, Irene, Howard Lasnik, and Robert May. 1991. Reciprocity and Plurality. Linguistic Inquiry 22(1), 63-101.

Hopper, Paul \& Sandra Thompson. 1980. Transitivity in grammar and discourse. Language 56.1:251-299.

Hosokawa, Komei. 1991. The Yawuru language of West Kimberley: a meaning-based description. Unpublished Ph.D. dissertation: ANU.

Huddleston, Rodney \& Geoffrey K. Pullum. 2002. The Cambridge Grammar of the English Language. Cambridge: Cambridge University Press.

Hurst, Peter. 2003. Syntactic representations of the Malagasy reciprocal construction. Honours Thesis, Department of Linguistics \& Applied Linguistics, University of Melbourne.

Jespersen, Otto. 1933. Essentials of English Grammar. London: George Allen \& Unwin.

Keen, Sandra. 1983. Yukulta. In R.M.W. Dixon \& Barry J. Blake, eds., Handbook of Australian Languages, Vol. 3. Canberra: ANU Press. Pp. 190-304.

Kemmer, Suzanne. 1993. The middle voice. Amsterdam / Philadelphia: John Benjamins.

King, Gareth. 1993. Modern Welsh: a comprehensive grammar. London \& New York: Routledge.

Kirton, Jean and Bella Charlie. 1996. Further aspects of the grammar of Yanyuwa, Northern Australia. Canberra: Pacific Linguistics.

König, Ekkehard, \& Kokutani, Shigehiro. 2006. Towards a typology of reciprocal constructions: focus on German and Japanese. In Linguistics.

Kulikov, Leonid. 2001. Causatives. In Martin Haspelmath, Ekkehard König, Wulf Österreicher \& Wolfgang Raible (eds.) Language Typology and Language Universals. Vol. 2. Berlin: de Gruyter. Pp. 886-898. 
La Fauci, Nunzio. 1992. Capitoli de morfosintassi siciliana antica: tassonomia dei costrutti medi e ausiliari perfettivi. In Studi linguistici e filolgici offerti a Girolamo Caracausi. Pp. 185-220. Palermo, Centro di studi filologici e linguistici siciliani.

Langendoen, D. Terence. 1978. The Logic of Reciprocity. Linguistic Inquiry 9(2): 177-197.

Langendoen, D. Terence \& Joël Magloire. 2003. The logic of reflexivity and reciprocity. In Andrew Barss (ed.), Anaphora: a Reference Guide. Oxford: Blackwells.

Laughren, Mary. 1992. Secondary predication as a diagnostic of underlying structure in Pama-Nyungan languages. In Iggy Roca (ed.) Thematic structure: its role in grammar. Berlin: Foris/Mouton de Gruyter. Pp. 199-246.

Laughren, Mary. 2001. Wanyi Reflexive-Reciprocal Constructions. Proceedings of the 2001 Conference of the Australian Linguistic Society. [insert web address]

Laughren, Mary, and Warlpiri Lexicography Group. (forthcoming). Warlpiri-English Encyclopaedic Dictionary, with English finder list. Alice Springs: IAD Press.

Lebeaux, David. 1983, A Distributional Difference between Reciprocals and Reflexives. Linguistic Inquiry 14.4: 723-730.

Leonovicheva, Z. 1962. Cheshskie vozvratnye glagoly s chstitej si i ix sootvetstvija v russkom jazyke. Uchenye zapiski LGU. Serija filologicheskix nauk 316 (64):149-163.

Loporcaro, Michele. 1998. Sintassi comparata dell'accordo participiale romanzo. Turin: Rosenberg \& Seller.

Loporcaro, Michele. Ms (2003 version). Auxiliation in Romance (binary, unary or triple), syntactic theory, and the typology of alignment.

Marsh, James. 1992. Martu Wangka-English Dictionary. Berrimah, N.T.: SIL.

Maslova, Elena. In press. Reciprocal and polyadic. (Remarkable reciprocals in Bantu). In V. Nedjalkov \& E. Geniusienie (eds.) Typology of reciprocal constructions.

Maslova, Elena \& Vladimir Nedjalkov. 2005. Reciprocal constructions. In Martin Haspelmath, Matthew Dryer, David Gil and Bernard Comrie (eds.), The World Atlas of Linguistic Structures. Oxford: OUP. Pp. 430-433. 
McGregor, William B. 1990. A functional grammar of Gooniyandi. Amsterdam: John Benjamins.

McGregor, William B. 1992. The semantics of ergative marking in Gooniyandi. Linguistics 30:275-318.

McGregor, William B. 1999. Reflexive and reciprocal constructions in Nyulnyulan languages. In Zygmunt Frajzyngier \& Traci C. Curl (eds.), Reciprocals: Form and Function. Amsterdam: John Benjamins. Pp. 85-122.

McKay, Graeme. 2000. Ndjébbana. In R.M.W. Dixon \& Barry J. Blake (eds.), Handbook of Australian Languages, Vol. 5. Melbourne: Oxford University Press.

Mchombo, Sam. 1991. Reciprocalization in Chichewa: a lexical account. Linguistic Analysis 21:3-22.

Mel'cuk, Igor A. 1979. Studies in dependency syntax. Ann Arbor: Karoma.

Merlan, Francesca. 1994. A grammar of Wardaman. Berlin: Mouton de Gruyter.

Mohanan, K.P. \& Mohanan, Tara. 1998. Strong and weak projection: lexical reflexives and reciprocals. In Miriam Butt and Wilhelm Geuder (eds.), The projection of arguments: lexical and compositional factors. Stanford: CSLI Publication. Pp. 165-194.

Moyse-Faurie, Claire. 1995. Le xâracùù, langue de Thio-Canala (NouvelleCalédonie). Paris: SELAF.

Mushin, Ilana. 2000. Karrwa Jangkurr. A guide to the Karrwa language. Unpublished Report, Borroloola Language Project.

Nash, David. 1986. Topics in Warlpiri grammar. New York: Garland (Outstanding Dissertations Series).

Nedjalkov, Vladimir P. 1991. Tipologija vzaimnyx konstrukcij. In A. V. Bondarko (ed.) Teorija funkcional'noj gramatiki: Zalogovost', Personal'nost', pp. 276-312. Leningrad: Nauka.

Newman, Paul. 2000. The Hausa language. An Encyclopaedic reference grammar. Yale University Press.

Nordlinger, Rachel. 1998. A grammar of Wambaya, Northern Territory, Australia. Canberra: Pacific Linguistics.

Norman, B.J. 1972. Perexodnost', zalog, vozvratnost'. Minsk: Izdatel'stvo BGU. 
Osumi, Midori. 1995. Tinrin grammar (Oceanic Linguistics Special Publication No. 25). Hawaii: University of Hawaii Press.

Quirk, Randolph \& Sydney Greenbaum. 1973. A University Grammar of English. London: Longman.

Rosen, Carol. 1981 [1988]. The Relational Structure of Reflexive Clauses. New York: Garland. [Ph.D diss., Harvard University 1981]

Rosen, Carol. 1982. The Unaccusative Hypothesis and the 'Inherent Clitic' Phenomenon in Italian. CLS 18:530-541,

Rumsey, Alan. 2000. Bunuba. In R.M.W. Dixon \& Barry J. Blake, eds., The Handbook of Australian Languages, vol. 5. Melbourne: Oxford University Press.

Simpson, Jane. 1991. Warlpiri morphosyntax: a lexicalist approach. Dordrecht: Kluwer Academic.

Simpson, Jane \& Joan Bresnan. 1983. Control and obviation in Warlpiri. Natural Language and Linguistic Theory 1.1:49-64.

Tamura, Suzuko. 2000. The Ainu language. Tokyo: Sanseido.

Verstraete, Jean-Christophe. MS. Same source, same target, different paths: from 'person' to reflexive in Umpithamu and other Paman languages.

Walsh, Michael. 1976. Ergative, locative and instrumental case inflections: Murinjpata. In R.M.W. Dixon (ed.) Grammatical categories in Australian languages. Canberra: AIAS. Pp. 405-8.

Wilkins, David. 1989. Mparntwe Arrernte (Aranda): studies in the structure and semantics of grammar. Unpublished Ph.D. dissertation, Australian National University.

Yallop, Colin. 1977. Alyawarra. An Aboriginal language of central Australia. Canberra: AIAS.

Yallop, Colin. 1982. Australian Aboriginal Languages. London: Andre Deutsch. Zeshan, Ulrike \& Sibaji Panda. Forthcoming. Reciprocals in Indo-Pakistani Sign Language. In Nicholas Evans, Alice Gaby, Steven Levinson \& Asifa Majid (eds.), Reciprocals and semantic typology. 


\section{Abbreviations:}

1 First person (singular if not followed by other indication of number marking)

2 Second person

3 Third person

12 First person inclusive (speaker plus hearer)

/ Acting upon, e.g. $3 / 1$ ' $1{ }^{\text {st }}$ singular subject acting upon third singular object'

I $\quad$ First noun class ( basically masculine $)$

IV fouth noun class (basically neuter)

A Transitive subject

ABS Absolutive

ACC Accusative

ASS Assertive

BEN Benefactive

COM Comitative

COMP Complement

COMPL Completive

CTP Contemporaneous

CTV Continuative

DAT Dative

DEM Demonstrative

Dish disharmonic kin relation

DO do (denominal verbalizer)

DS different subject

DU Dual

DYAD Dyadic

eB elder brother

ERG Ergative

EUPH Euphony

FUT future

hi higher animate ( basically human)

IMPF Imperfective

INC inclusive 
INF infinitive

IND Indicative

INF Infinitive

INSTR instrumental

INTENT intentive

INTR intransitive

IRR irrealis

Masc Masculine

MPROP Modal proprietive (marks objects and other non-subject actants in future and desiderative clauses)

$\mathrm{N} \quad$ nominalizer

NM non-masculine

NOM Nominative

NPST Non-past

$\mathrm{O} \quad$ Object argument of clause (in contradistinction to subject)

Obj Object pronominal prefix form (may include both indirect and direct objects in some languages)

OBJ.COMP Object complement

OBL Oblique

PART particle

PAUC Paucal

PI Past imperfective

PL Plural

POSS Possessive

POSSD Possessed

POT Potential

PP Past perfective

PR Present

PROP Proprietive

PST Past

Q Question

R Realis

RA2 Form-based name of particular auxiliary 
Valency mismatches and the coding of reciprocity in Australian languages

$\begin{array}{ll}\text { REC } & \text { Reciprocal } \\ \text { REFL } & \text { Reflexive } \\ \text { REL } & \text { Relative } \\ \text { RR } & \text { Reflexive/reciprocal } \\ \text { S } & \text { Intransitive subject }\end{array}$

SUB(J) subject

TAM tense/aspect $/ \mathrm{mood}$ indicator

TOP topic

TR transitive

WU2 form-based name of particular auxiliary 
Table 1. Languages and sources

\begin{tabular}{|c|c|c|}
\hline Language & Family; Location & Source \\
\hline $\begin{array}{l}\text { Alyawarr } \\
\text { (=Alyawarra) }\end{array}$ & $\begin{array}{l}\text { Pama-Nyungan, C. } \\
\text { Australia }\end{array}$ & $\begin{array}{l}\text { Yallop 1977, Green } \\
1992\end{array}$ \\
\hline Bunaba & $\begin{array}{l}\text { Bunaban, Kimberley, } \\
\text { Western Australia }\end{array}$ & Rumsey 2000 \\
\hline Dalabon & Gunwinyguan, N.T. & $\begin{array}{l}\text { Evans et al 2004, } \\
\text { Evans field notes }\end{array}$ \\
\hline Dyirbal & $\begin{array}{l}\text { Pama-Nyungan, N.E. } \\
\text { Queensland }\end{array}$ & Dixon 1972 \\
\hline Gooniyandi & $\begin{array}{l}\text { Bunaban, Kimberley, } \\
\text { Western Australia }\end{array}$ & McGregor 1990 \\
\hline Guugu Yimidhirr & $\begin{array}{l}\text { Pama-Nyungan; E. } \\
\text { Cape York, } \\
\text { Queensland }\end{array}$ & Haviland 1979 \\
\hline Karrwa & $\begin{array}{l}\text { Garrwan, Gulf of } \\
\text { Carpentaria, } \\
\text { Northern Territory }\end{array}$ & Furby \& Furby 1977 \\
\hline Kayardild & $\begin{array}{l}\text { Tangkic, Gulf of } \\
\text { Carpentaria, N.W. } \\
\text { Queensland }\end{array}$ & Evans 1995 \\
\hline Kuuk Thaayorre & $\begin{array}{l}\text { Pama-Nyungan; W. } \\
\text { Cape York, } \\
\text { Queensland }\end{array}$ & Gaby 2006 \\
\hline Ndjébbana & Maningrida, N.T. & McKay 2000 \\
\hline Ngiyambaa & $\begin{array}{l}\text { Pama-Nyungan; New } \\
\text { South Wales }\end{array}$ & Donaldson 1980 \\
\hline Umpithamu & $\begin{array}{l}\text { Pama-Nyungan; } \\
\text { central Cape York, } \\
\text { Queensland }\end{array}$ & Verstraete MS \\
\hline Wambaya & $\begin{array}{l}\text { Mindi, Barkly } \\
\text { Tableland, N.T. }\end{array}$ & Nordlinger 1998 \\
\hline
\end{tabular}




\begin{tabular}{|c|c|c|}
\hline Wanyi & $\begin{array}{l}\text { Garrwan, Gulf of } \\
\text { Carpentaria, } \\
\text { Northern Territory }\end{array}$ & Laughren 2001 \\
\hline Warlpiri & $\begin{array}{l}\text { Pama-Nyungan; } \\
\text { Central Australia }\end{array}$ & $\begin{array}{l}\text { Hale 1981, 1982, } \\
\text { Hale et al 1995, } \\
\text { Laughren et al f/c, } \\
\text { Nash 1986, Simpson } \\
\text { 1991, Simpson \& } \\
\text { Bresnan } 1983\end{array}$ \\
\hline Warluwarra & $\begin{array}{l}\text { Pama-Nyungan; W. } \\
\text { Queensland }\end{array}$ & Breen forthcoming \\
\hline Yanyuwa & $\begin{array}{l}\text { Pama-Nyungan; Gulf } \\
\text { of Carpentaria. } \\
\text { Northern Territory }\end{array}$ & $\begin{array}{l}\text { Kirton \& Charlie } \\
1996\end{array}$ \\
\hline Yaraldi & $\begin{array}{l}\text { Pama-Nyungan? }{ }^{67} ; \\
\text { Murray River, South } \\
\text { Australia }\end{array}$ & Cerin 1994 \\
\hline Yawurru & $\begin{array}{l}\text { Nyulnyulan, } \\
\text { Kimberley, Western } \\
\text { Australia }\end{array}$ & $\begin{array}{l}\text { Hosokawa 1991, } \\
\text { McGregor } 1999\end{array}$ \\
\hline Yukulta & $\begin{array}{l}\text { Tangkic, Gulf of } \\
\text { Carpentaria, N.W. } \\
\text { Queensland }\end{array}$ & Keen 1983 \\
\hline
\end{tabular}

\footnotetext{
${ }^{67}$ Though traditionally classed as Pama-Nyungan, there are so few Pama-Nyungan features that the classification of this language must be regarded as still unresolved.
} 
Table 2. Constructional manifestations of intransitivity and reciprocal strategy

$\mathrm{V}=$ Verb-coded reciprocal (by affix)

$\mathrm{P}=$ Reciprocal pronoun (free, bound or clitic)

Material in italics represents exceptions to the null hypothesis that clauses with verbcoded reciprocals will behave as pure intransitives, and clauses with pronoun-coded reciprocals will behave as pure transitives (limiting the discussion to base transitive vebs)

\begin{tabular}{|c|c|c|c|}
\hline Language & Coding & Indicators of intransitivity & Indicators of transitivity \\
\hline Alyawarr & V & one overt argument & $\begin{array}{l}\text { ergative case on instruments; } \\
\text { ergative marking on secondary } \\
\text { predicates }\end{array}$ \\
\hline Badjala & V & $\begin{array}{l}\text { one overt argument; subject may } \\
\text { take nominative case }\end{array}$ & subject may take ergative case \\
\hline Bunuba & V & $\begin{array}{l}\text { one overt argument; subject may } \\
\text { take nominative case }\end{array}$ & subject may take ergative case \\
\hline Dalabon & V & $\begin{array}{l}\text { one overt argument; subject in } \\
\text { nominative case }\end{array}$ & $\begin{array}{l}\text { part nouns incorporated as though } \\
\text { linked to an object; two arguments } \\
\text { present in reciprocals formed from } \\
\text { ditransitive verbs; subjects of } \\
\text { reciprocals formed from } \\
\text { ditransitive verbs may take } \\
\text { instrumental case }\end{array}$ \\
\hline Dyirbal & V & $\begin{array}{l}\text { one overt argument; subject in } \\
\text { nominative case }\end{array}$ & \\
\hline Gooniyandi & V & one overt argument & subject marked ergative \\
\hline Kayardild & V & one overt argument & $\begin{array}{l}\text { case of part nouns linked to } \\
\text { (suppressed) object }\end{array}$ \\
\hline Kuuk Thaayorre & & $\begin{array}{l}\text { one overt argument; subject may } \\
\text { take nominative case }\end{array}$ & subject may take ergative case \\
\hline
\end{tabular}




\begin{tabular}{|c|c|c|c|}
\hline Ndjébbana & $\mathrm{V}$ & $\begin{array}{l}\text { one overt argument; intransitive } \\
\text { pronominal prefixes representing } \\
\text { subject }\end{array}$ & \\
\hline Ngiyambaa & $\mathrm{V}$ & $\begin{array}{l}\text { one overt argument; subject in } \\
\text { nominative case }\end{array}$ & \\
\hline Yawuru & $\mathrm{V}$ & one overt argument & transitive prefix on verb \\
\hline Yukulta & $\mathrm{V}$ & $\begin{array}{l}\text { one overt argument; intransitive } \\
\text { form of auxiliary; subject in } \\
\text { nominative case; instrumental } \\
\text { adjuncts in comitative case }\end{array}$ & \\
\hline Wambaya & $\mathrm{V}^{68}$ & $\begin{array}{l}\text { subject in nominative case; } \\
\text { complements of perception verbs } \\
\text { show subject-control }\end{array}$ & \\
\hline Umpithamu & Adverb & $\begin{array}{l}\text { one overt argument; subject in } \\
\text { nominative case }\end{array}$ & $\begin{array}{l}\text { part nouns may occupy preverbal } \\
\text { position characteristic of objects } \\
\text { or object-linked body parts }\end{array}$ \\
\hline Karrwa & $\mathrm{P}$ & $\begin{array}{l}\text { one overt argument; subject in } \\
\text { nominative case }\end{array}$ & \\
\hline Wanyi & $\mathrm{P}$ & one overt argument & subject takes ergative \\
\hline Warlpiri & $\mathrm{P}$ & & $\begin{array}{l}\text { subject marked ergative; ergative } \\
\text { case on instruments; secondary } \\
\text { predicates linked to subject take } \\
\text { ergative case; secondary } \\
\text { predicates can be linked to object } \\
\text { position; ergative outer case } \\
\text { agreement on instruments marked } \\
\text { with proprietive; body parts may } \\
\text { agree }\end{array}$ \\
\hline
\end{tabular}

\footnotetext{
${ }^{68}$ Although we do not analyse it as a pronominal, this reciprocal marker appears in the same morphological position as object bound pronouns on the second position auxiliary (Nordlinger 1998), and may have originated as a bound reflexive/reciprocal pronoun. Note also that it is classified as a V (rather than P) here only in the broader sense since it is marked on the auxiliary, rather than the lexical verb itself.
} 
Valency mismatches and the coding of reciprocity in Australian languages

\begin{tabular}{|l|l|l|l|}
\hline Warluwarra & $\mathrm{P}$ & one overt argument & subject marked ergative \\
\hline Yanyuwa & $\mathrm{P}^{69}$ & $\begin{array}{l}\text { one overt argument } \text {; reciprocal } \\
\text { pronominal prefixes typically } \\
\text { derived from intransitive form; } \\
\text { subject in nominative case }\end{array}$ & \\
\hline Yaraldi & $\mathrm{P}$ & $\begin{array}{l}\text { reciprocal pronouns based on } \\
\text { intransitive form }\end{array}$ & \\
\hline
\end{tabular}

\section{Authors:}

Nick Evans

nrde@unimelb.edu.au
Alice Gaby

agaby@unimelb.edu.au
Rachel Nordlinger

racheln@unimelb.edu.au

School of Languages and Linguistics

University of Melbourne

VIC 3010

AUSTRALIA

\footnotetext{
${ }^{69}$ The form of Yanyuwa reciprocal marking does not fit neatly into either the verbal or pronominal category. See discussion in text for a fuller characterisation.
} 


\section{University Library}

- MIN E R VA A gateway to Melbourne's research publications

Minerva Access is the Institutional Repository of The University of Melbourne

Author/s:

EVANS, NICHOLAS; GABY, ALICE; NORDLINGER, RACHEL

Title:

Valency mismatches and the coding of reciprocity in Australian languages

Date:

2006-11

Citation:

Evans, Nicholas and Gaby, Alice and Nordlinger, Rachel (2006) Valency mismatches and the coding of reciprocity in Australian languages.

Persistent Link:

http://hdl.handle.net/11343/34556

File Description:

Valency mismatches and the coding of reciprocity in Australian languages 


\section{University Library}

\section{- M M N E R VA A gateway to Melbourne's research publications}

Minerva Access is the Institutional Repository of The University of Melbourne

\section{Author/s:}

EVANS, N;Gaby,;NORDLINGER, R

Title:

Valency mismatches and the coding of reciprocity in Australian languages

Date:

2007

Citation:

EVANS, N., Gaby, \& NORDLINGER, R. (2007). Valency mismatches and the coding of reciprocity in Australian languages. Linguistic Typology, 11 (3), pp.541-597. https:// doi.org/10.1515/LINGTY.2007.033.

Persistent Link:

http://hdl.handle.net/11343/28176 